\title{
Rol del farmacéutico en la atención integral de pacientes con hepatitis C: revisión sistemática
}

\section{The role of pharmacists in the comprehensive care of patients with hepatitis C: a systematic review}

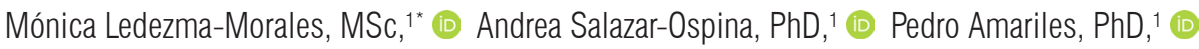
Jaime Alejandro Hincapié-García, MSc. ${ }^{1}$

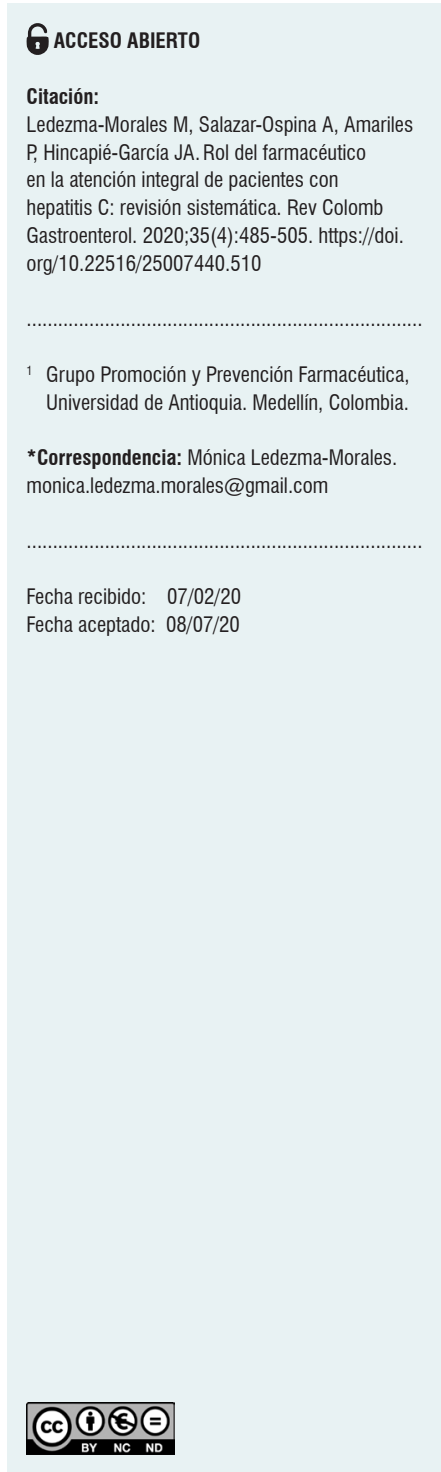

\begin{abstract}
Resumen
Objetivo: identificar y caracterizar las acciones/intervenciones realizadas desde los servicios farmacéuticos en el abordaje de pacientes con hepatitis $\mathrm{C}$ y proponer una vía clínica para la gestión de la enfermedad que incluya la participación del farmacéutico. Método: revisión sistemática en PubMed y EMBASE empleando los términos "Hepatitis C", "Pharmaceutical Services", "Community Pharmacy Services", y "Pharmacies"; artículos publicados hasta el 31 de marzo de 2019, cuyo tema central fueran las actividades realizadas por los servicios farmacéuticos en la atención a pacientes con hepatitis $\mathrm{C}$. Se recopiló información sobre la actividad realizada, responsable, si la intervención era individual o colectiva y el entorno de aplicación. Las actividades se agruparon en promoción y prevención, gestión administrativa, atención farmacéutica, investigación y otros servicios de apoyo. De acuerdo con esto, se propuso una vía clínica para el manejo de la hepatitis $C$ con participación del farmacéutico. Resultados: se incluyeron 60 artículos, principalmente de estudios descriptivos. La mayoría de las publicaciones reportó intervenciones realizadas en Estados Unidos y España. Se identificó la participación del personal farmacéutico en cada una de las etapas del proceso de atención, que incluye la provisión de servicios de reducción del daño, tamizaje del virus de la hepatitis $C$, vinculación de los pacientes al tratamiento, prescripción de medicamentos y órdenes de laboratorio. Conclusiones: se identifican y caracterizan las acciones/intervenciones realizadas desde el servicio farmacéutico para el manejo de la hepatitis $\mathrm{C}$ y se propone una vía clínica en la que se integran los servicios profesionales farmacéuticos a las demás actividades de la atención del paciente.
\end{abstract}

\section{Palabras clave}

Servicios farmacéuticos, manejo de atención al paciente, hepatitis $C$, antivirales, atención integral de salud.

\begin{abstract}
Objective: To identify and characterize the actions/interventions carried out by pharmaceutical services to approach patients with Hepatitis $\mathrm{C}$ and propose a clinical pathway for managing the disease that involves pharmacists. Methodology: A systematic review was conducted in PubMed and EMBASE using the terms "Hepatitis C," "Pharmaceutical Services," "Community Pharmacy Services," and "Pharmacies." Articles published until March 31,2019 , whose central topic was the activities carried out by the pharmaceutical services in the care of patients with Hepatitis $\mathrm{C}$, were included. Information on the activity performed, the person in charge, whether the intervention was individual or collective, and the implementation environment was collected. The activities were grouped into promotion and prevention, administrative management, pharmaceutical care, research, and other support services. Based on the above, a clinical pathway for the management of Hepatitis $\mathrm{C}$ involving pharmacists was proposed. Results: Sixty articles were included, mainly descriptive studies. Most publications reported interventions in the United States and Spain. Pharmaceutical staff involvement was identified at each stage of the care process, including the provision of harm reduction services, Hepatitis $C$ virus screening, enrolling patients to treatment, medication prescription, and laboratory orders. Conclusions: The actions/interventions carried out by the pharmaceutical service for Hepatitis $\mathrm{C}$ management were identified and characterized. A clinical pathway has been proposed to integrate professional pharmaceutical services with other patient care activities.
\end{abstract}

\section{Keywords}

Pharmacy Services; Patient Care Management; Hepatitis C; Antivirals; Comprehensive Health Care. 


\section{INTRODUCCIÓN}

El tratamiento para la infección por el virus de la hepatitis $\mathrm{C}$ (VHC) ha avanzado notablemente en la última década, debido al desarrollo de antivirales de acción directa (AAD), que constituyen tratamientos más sencillos, cortos, eficaces y mejor tolerados, en comparación con los esquemas convencionales (interferón y ribavirina) $(1,2)$. Los AAD han representado mejoras en la adherencia al tratamiento y disminución en la interrupción temprana del mismo. Sin embargo, aún existen barreras para el acceso y continuidad del tratamiento, especialmente en poblaciones vulnerables, en las cuales existen barreras relacionadas con el bajo nivel educativo, el estatus socioeconómico, la educación sobre la salud y el abuso de sustancias psicoactivas (1).

En este sentido, los farmacéuticos pueden respaldar la atención en salud de los pacientes con hepatitis $\mathrm{C}$ como proveedores no médicos $(3,4)$. Estos últimos pueden mejorar el acceso de los pacientes al tratamiento y a los servicios de salud $(5,6)$, haciendo parte de equipos multidisciplinarios y realizando un seguimiento clínico cercano y continuo para garantizar el cumplimiento de la farmacoterapia (1).

Aunque varios autores han descrito las actividades realizadas desde el servicio farmacéutico en la prevención, tamizaje y manejo de la hepatitis $\mathrm{C}$, estas se han publicado de manera aislada y no se dispone de información consolidada sobre el tema. Por tanto, el objetivo de este trabajo fue identificar y caracterizar las acciones e intervenciones realizadas desde los servicios farmacéuticos en el abordaje de pacientes con hepatitis $\mathrm{C} y$, con ello, proponer una vía clínica con participación del farmacéutico para el manejo integral de dicha enfermedad.

\section{MÉTODOS}

\section{Identificación y selección de artículos}

Se realizó una revisión en PubMed/Medline y EMBASE utilizando las estrategias de búsqueda: ("Hepatitis C”[Mesh]) AND (((( “Pharmaceutical Services"[Mesh]) OR "Pharmaceutical Services, Online" [Mesh]) OR "Pharmacy Service, Hospital"[Mesh]) OR "Community Pharmacy Services"[Mesh]) OR "Pharmacies"[Mesh]), y 'hepatitis c'/exp AND 'pharmaceutical care'/exp, respectivamente, con filtros para artículos publicados hasta el 31 de marzo de 2019, en inglés o español, estudios realizados en humanos, con acceso a texto completo. Se incluyeron editoriales, notas, noticias, comentarios, resúmenes de conferencia y artículos originales que describieran acciones e intervenciones realizadas desde el servicio farmacéutico dirigidos a la atención de pacientes con hepatitis $\mathrm{C}$.
Las publicaciones identificadas se evaluaron de forma pareada. Inicialmente, se revisaron el título y el resumen para decidir su elegibilidad. Posteriormente, se hizo una lectura del texto completo de los artículos preseleccionados y se excluyeron los que hacían referencia a artículos previamente incluidos o que no proporcionaban información nueva. La búsqueda se complementó con publicaciones consideradas relevantes, referenciadas en los artículos incluidos (Figura 1).

\section{Extracción de datos y categorización de la información}

La información obtenida de cada artículo incluido se estructuró en una base de datos con las siguientes variables: acción/ intervención, descripción de la actividad, tipo de intervención (individual o colectiva), responsable (farmacéutico profesional, técnico u otro), entorno en el que fue realizada la actividad (ambulatorio, hospitalario, comunitario o penitenciario), categorías de la atención en salud (gestión de la salud pública, promoción de la salud, diagnóstico, tratamiento, rehabilitación o paliación) y publicación de referencia.

Las acciones e intervenciones identificadas se agruparon en categorías según las funciones del servicio farmacéutico: promoción y prevención, gestión administrativa, atención farmacéutica, investigación y otros servicios de apoyo.

Para la comprensión de los resultados, se consolidó la información de todos los artículos según las acciones e intervenciones descritas. Así mismo, se identificó información sobre las estrategias empleadas para evaluar la calidad de las intervenciones identificadas.

\section{RESULTADOS}

\section{Estudios identificados}

Se incluyeron 60 artículos en la revisión (Figura 1).El $83 \%$ de las publicaciones se relacionó con actividades farmacéuticas realizadas principalmente en Estados Unidos (EE. UU.) y España. El $45 \%$ de las referencias se publicaron entre 2016 y 2019 (Tabla 1).

\section{Acciones e intervenciones del servicio farmacéutico en el manejo de pacientes con hepatitis C crónica}

En la Tabla 2 se presentan las acciones/intervenciones, el personal responsable, el entorno y la referencia de los artículos que las describen.

Para definir el entorno, se utilizaron 4 clasificaciones:

1. Comunitario, si las actividades eran realizadas en oficinas de farmacia o boticas, que usualmente se encuentran ubicadas en los barrios y prestan un servicio independiente de otras instituciones asistenciales. 


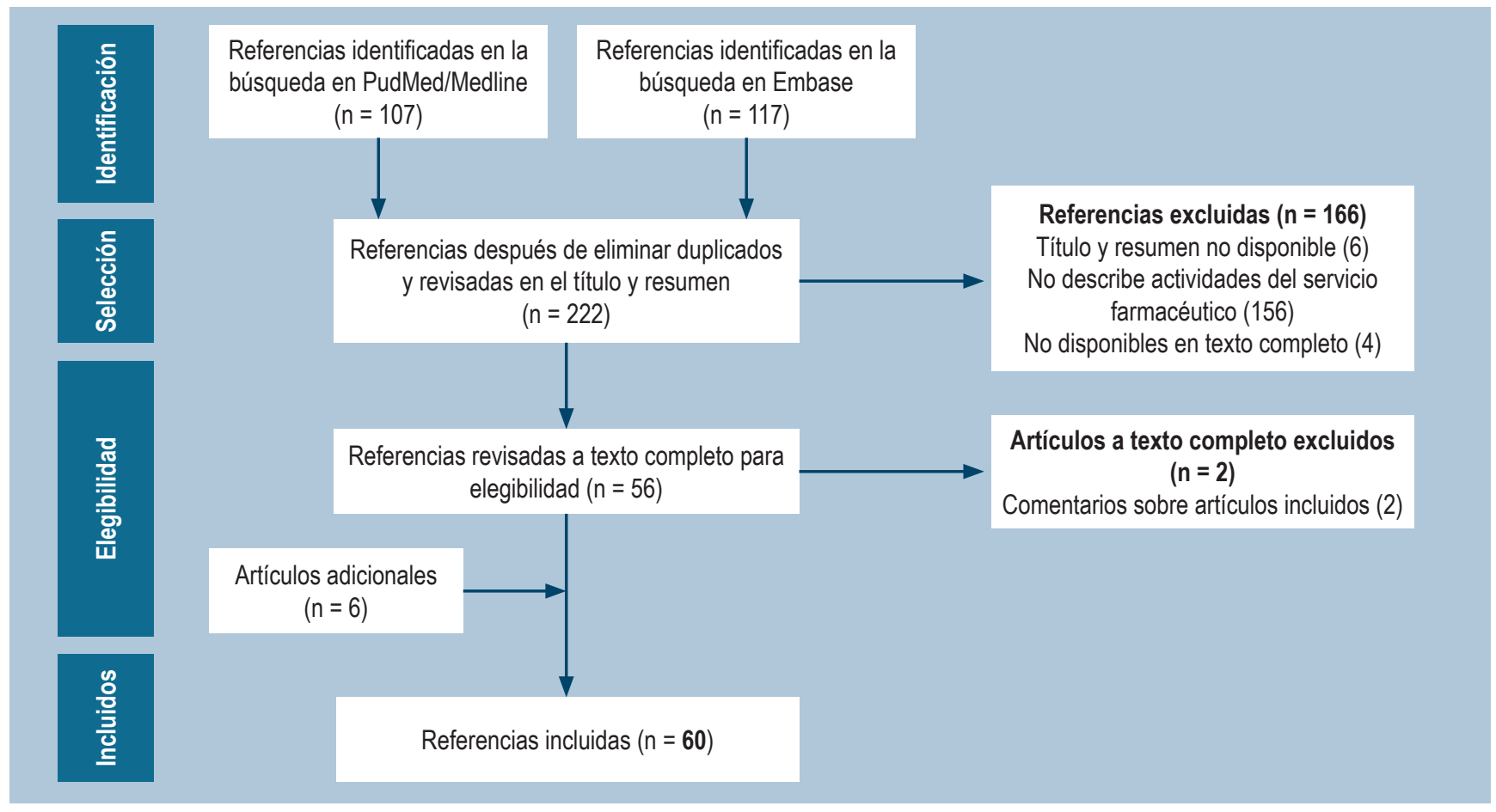

Figura 1. Diagrama de flujo de las referencias incluidas en la revisión.

2. Ambulatorio, si las actividades eran ofrecidas por servicios farmacéuticos e instituciones que ofrecen consulta externa; es decir, a pacientes que no requieren hospitalización.

3. Hospitalario, cuando las actividades eran desarrolladas durante la atención de pacientes hospitalizados.

4. Penitenciario, para referirse a las actividades ejercidas en la atención de pacientes bajo régimen carcelario.

\section{Promoción y prevención}

\section{Información y educación al paciente (7-11)}

- Actividades educativas orientadas a aumentar la conciencia pública e individual sobre el mecanismo de transmisión de las hepatitis $\mathrm{B}$ y $\mathrm{C}$ y cómo prevenirlas.

- Entrega de material educativo sobre la hepatitis C y carteles visibles en la farmacia, que alienten a los pacientes a preguntar a los profesionales médicos sobre sus problemas de salud.

\section{Provisión de vacunas (8)}

Servicio de vacunación contra la hepatitis A y B y de otras vacunas que podrían ser necesarias en pacientes con enfermedad hepática crónica.

\section{Servicios de reducción del daño $(9,12-16)$}

Servicios claves para prevenir las infecciones de transmisión sexual en poblaciones de riesgo como usuarios de drogas inyectables (UDI). Pueden incluir:

- Educación y entrega de material educativo sobre virus de inmunodeficiencia humana (VIH), VHC y provisión de jeringas estériles, ya sea sin prescripción médica o en programas de intercambio de jeringas.

- Entrega de contenedores de objetos cortopunzantes para desechar jeringas.

- Entrega de material estéril como jeringas, agujas, agua y tapas de metal.

- Eliminación de jeringas usadas.

- Naloxona iniciada por el farmacéutico (según los protocolos para el manejo de sobredosis de opioides).

- Entrenamiento o información sobre cómo inyectar de manera segura y prevenir la sobredosis.

- Entrega de condones gratis y remisión a servicios sociales, centros de referencia o al médico para tratamiento.

\section{Tamizaje de VHC (7-10, 17-21)}

Suministro de pruebas rápidas de VHC seguido de un proceso de asesoramiento o derivación al médico de acuerdo con el resultado de esta. 
Tabla 1. Características de los artículos incluidos en la revisión $(n=60)$

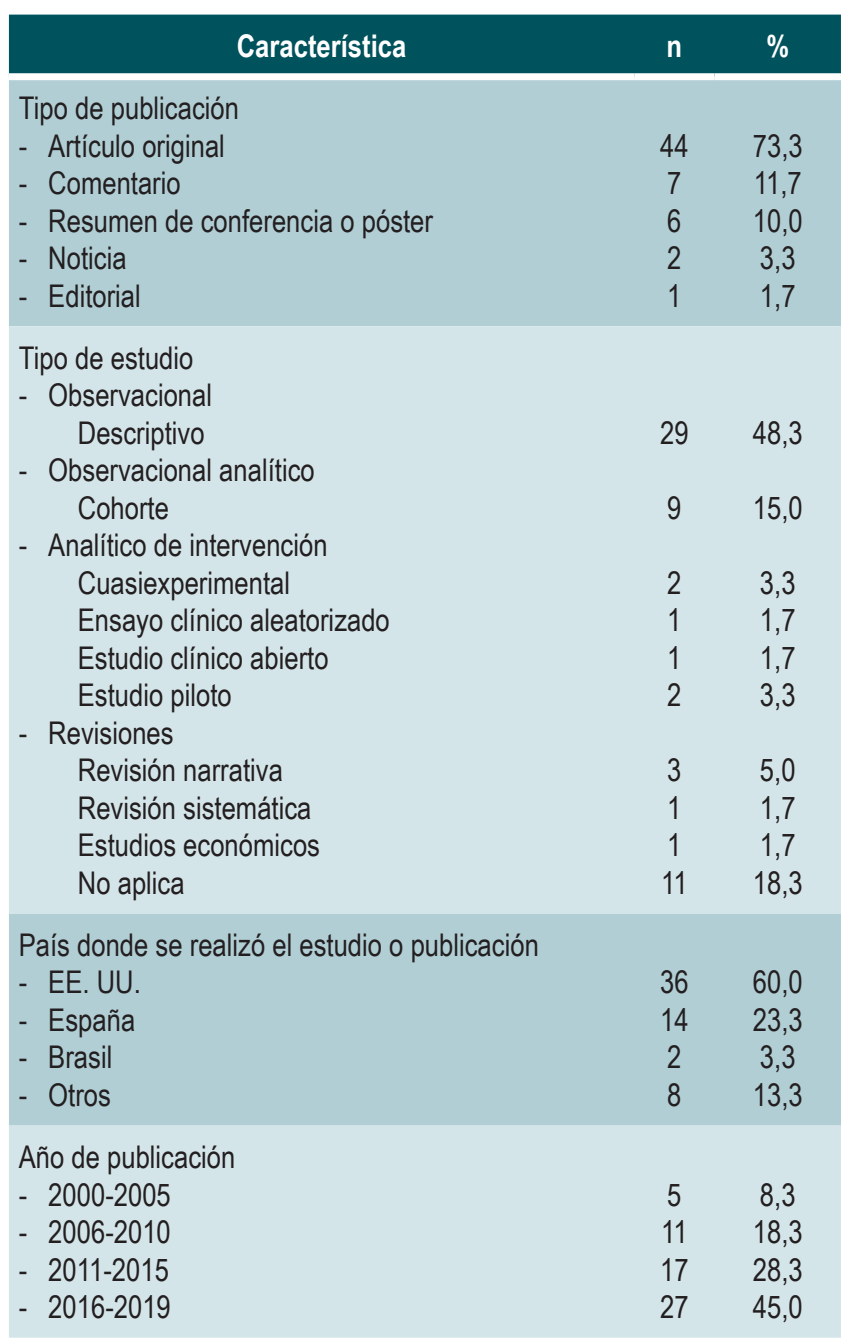

\section{Gestión administrativa}

\section{Acompañamiento administrativo $(1,6,20,22-26)$}

Obtención de información sobre los parámetros clínicos basales del paciente (resultados de laboratorio, estadificación de la fibrosis, notas clínicas del personal médico) y datos sociodemográficos para completar los registros de preautorización requeridos por las empresas aseguradoras, sistema de salud o proveedores de atención médica. Esta información puede documentarse en la historia clínica del paciente. Si se dispone de un programa integral, el personal farmacéutico puede realizar la solicitud del envío del medicamento a la farmacia de preferencia del paciente y programar una visita para el inicio del tratamiento.

\section{Adquisición y distribución de medicamentos (8)}

En adición al proceso habitual de adquisición y distribución de medicamentos, el farmacéutico puede identificar pacientes en riesgo de no adherencia según el historial de reabastecimiento de sus medicamentos. Adicionalmente, puede garantizar que el paciente reciba los medicamentos a tiempo, agilizar el proceso de autorización previa y asegurarse de que todos los medicamentos se actualicen en el sistema de farmacia para revisar las posibles interacciones entre medicamentos.

\section{Atención farmacéutica}

\section{Dispensación de medicamentos (1, 22, 25, 27-31)}

Puede realizarse durante la consulta de seguimiento con el farmacéutico mediante la coordinación con el paciente para que se dispense en la farmacia más cercana, por envío al domicilio del paciente o en una terapia directamente observada. En algunos contextos, puede tenerse apoyo de estudiantes de farmacia para que, por vía telefónica, verifiquen con el paciente si su medicamento ha sido entregado en la farmacia.

\section{Seguimiento farmacoterapéutico (presencial o} telefónico) (1, 3, 5, 8, 10, 20, 25, 27-30, 32-48)

Es un proceso dirigido a mejorar la adherencia al tratamiento $y$, por tanto, a una mayor probabilidad de lograr la respuesta virológica sostenida y evitar el desarrollo de resistencias. Permite identificar y resolver, de manera oportuna, los problemas relacionados con medicamentos que puedan aparecer durante el tratamiento.

Por lo general, se realiza mensualmente de manera presencial o vía telefarmacia, dependiendo de las necesidades del paciente y de los recursos disponibles. Se puede complementar con llamadas periódicas, especialmente en aquellos pacientes en quienes se hayan detectado factores de riesgo para no adherencia.

Incluye:

- Evaluación inicial por el farmacéutico (entrevista farmacéutica: en esta se recoge información sociodemográfica, historia social [consumo de alcohol, abuso de sustancias]), problemas de salud, antecedentes alérgicos, farmacoterapia ambulatoria (principios activos, régimen de dosificación y vía de administración), forma de uso de medicamentos y uso de terapias alternativas.

- Validación de la farmacoterapia.

- Revisión de antecedentes de inmunización.

- Verificación de órdenes de laboratorio y medicamentos.

- Evaluación de la adherencia y de la efectividad del tratamiento. 
Tabla 2. Acciones e intervenciones del servicio farmacéutico en el manejo de pacientes con hepatitis C crónica: resultados de la revisión

\begin{tabular}{|c|c|c|c|c|c|}
\hline Categoria/actividad & Tipo de intervención & Responsable & Entorno & Categoría & Referencias \\
\hline \multicolumn{6}{|l|}{ Promoción y prevención } \\
\hline - Información y educación al paciente & Individual y colectiva & Farmacéutico & Comunitario & $\begin{array}{l}\text { Gestión de la } \\
\text { salud pública }\end{array}$ & $(7-11)$ \\
\hline - Provisión de vacunas & Colectiva & Farmacéutico & Comunitario & $\begin{array}{l}\text { Gestión de la } \\
\text { salud pública }\end{array}$ & (8) \\
\hline - Servicios de reducción del daño & Colectiva & $\begin{array}{l}\text { Personal farmacéutico } \\
\text { (profesional, técnico) }\end{array}$ & Comunitario & $\begin{array}{l}\text { Gestión de la } \\
\text { salud pública }\end{array}$ & $(9,12-16)$ \\
\hline - Tamizaje de VHC & Colectiva & Farmacéutico & Comunitario & Diagnóstico & $(7-10,17-21)$ \\
\hline \multicolumn{6}{|l|}{ Gestión administrativa } \\
\hline $\begin{array}{l}\text { - Acompañamiento administrativo } \\
\text { (autorización de tratamiento) }\end{array}$ & Individual & $\begin{array}{l}\text { Personal farmacéutico } \\
\text { (profesional, técnico o estudiantes } \\
\text { de farmacia); enfermero } \\
\text { especializado en hepatología }\end{array}$ & $\begin{array}{l}\text { Ambulatorio } \\
\text { Comunitario }\end{array}$ & Tratamiento & $(1,6,20,22-26)$ \\
\hline $\begin{array}{l}\text { - Adquisición y distribución de } \\
\text { medicamentos }\end{array}$ & Individual & Farmacéutico & $\begin{array}{l}\text { Ambulatorio } \\
\text { Hospitalario }\end{array}$ & Tratamiento & (8) \\
\hline \multicolumn{6}{|l|}{ Atención farmacéutica } \\
\hline - Dispensación de medicamentos & Individual & $\begin{array}{l}\text { Personal farmacéutico } \\
\text { (profesional, técnico o } \\
\text { estudiantes de farmacia) }\end{array}$ & $\begin{array}{l}\text { Ambulatorio } \\
\text { Comunitario }\end{array}$ & Tratamiento & $(1,22,25,27-31)$ \\
\hline $\begin{array}{l}\text { - Seguimiento farmacoterapéutico } \\
\text { (presencial o telefónico) }\end{array}$ & Individual & Farmacéutico & $\begin{array}{l}\text { Ambulatorio } \\
\text { Hospitalario } \\
\text { Comunitario }\end{array}$ & Tratamiento & $\begin{array}{l}(1,3,5,8,10,20 \\
25,27-30,32-48)\end{array}$ \\
\hline $\begin{array}{l}\text { - Educación al paciente y promoción de } \\
\text { la adherencia }\end{array}$ & Individual & $\begin{array}{l}\text { Personal farmacéutico } \\
\text { (profesional, técnico o } \\
\text { estudiantes de farmacia) }\end{array}$ & $\begin{array}{l}\text { Ambulatorio } \\
\text { Hospitalario } \\
\text { Comunitario }\end{array}$ & Tratamiento & $\begin{array}{l}(8,11,20,23,27, \\
30,32-36,38,40, \\
46,49-51)\end{array}$ \\
\hline $\begin{array}{l}\text { - Farmacovigilancia: detección, } \\
\text { evaluación, notificación de reacciones } \\
\text { adversas al medicamento y } \\
\text { recomendaciones para su manejo }\end{array}$ & Individual & Farmacéutico & $\begin{array}{l}\text { Ambulatorio } \\
\text { Hospitalario } \\
\text { Comunitario }\end{array}$ & Tratamiento & $\begin{array}{l}(1,8,11,22,29 \\
33,35,36,38 \\
45,47,52,53)\end{array}$ \\
\hline \multicolumn{6}{|l|}{ Investigación } \\
\hline - Investigación clínica & Colectiva & Farmacéutico & $\begin{array}{l}\text { Ambulatorio } \\
\text { Hospitalario }\end{array}$ & $\begin{array}{l}\text { Gestión de la } \\
\text { salud pública }\end{array}$ & (8) \\
\hline \multicolumn{6}{|l|}{ Otros servicios de apoyo } \\
\hline $\begin{array}{l}\text { Desarrollo de sistemas de } \\
\text { información y de soporte de } \\
\text { decisiones clínicas }\end{array}$ & Colectiva & $\begin{array}{l}\text { Farmacéutico, médicos } \\
\text { especialistas, experto } \\
\text { informático }\end{array}$ & $\begin{array}{l}\text { Ambulatorio } \\
\text { Hospitalario } \\
\text { Penitenciario }\end{array}$ & $\begin{array}{l}\text { Gestión de la } \\
\text { salud pública }\end{array}$ & $\begin{array}{l}(20,33,44,45 \\
54)\end{array}$ \\
\hline $\begin{array}{l}\text { - Participación en el equipo } \\
\text { multidisciplinario }\end{array}$ & Individual & Farmacéutico & $\begin{array}{l}\text { Ambulatorio } \\
\text { Hospitalario }\end{array}$ & Tratamiento & (33) \\
\hline $\begin{array}{l}\text { - Acompañamiento entre las } \\
\text { transiciones de la atención }\end{array}$ & Individual & Farmacéutico & $\begin{array}{l}\text { Ambulatorio } \\
\text { Hospitalario }\end{array}$ & Tratamiento & $(3,8,33)$ \\
\hline - Grupo de soporte & Colectiva & Equipo multidisciplinario & Comunitario & $\begin{array}{l}\text { Promoción de } \\
\text { la salud }\end{array}$ & $(55)$ \\
\hline $\begin{array}{l}\text { - Envío de cartas de motivación y } \\
\text { correos }\end{array}$ & Individual & $\begin{array}{l}\text { Personal farmacéutico } \\
\text { (profesional, técnico o } \\
\text { estudiantes de farmacia) }\end{array}$ & Ambulatorio & Tratamiento & $(56)$ \\
\hline Capacitación a profesionales de la salud & Colectiva & Farmacéutico & $\begin{array}{l}\text { Ambulatorio } \\
\text { Hospitalario }\end{array}$ & $\begin{array}{l}\text { Gestión de la } \\
\text { salud pública }\end{array}$ & $(8,47)$ \\
\hline
\end{tabular}


- Intervención farmacéutica (si aplica).

- En caso de que el paciente consuma alcohol o sustancias psicoactivas, el farmacéutico puede proporcionar información sobre la importancia de la abstinencia del alcohol y recomendar sitios para el soporte del abandono del uso de dichas sustancias.

\section{Educación para el paciente y promoción de la adherencia $(8,11,20,23,27,30,32-36,38,40,46$, 49-51)}

Es un proceso continuo que se realiza durante las diferentes visitas de seguimiento; sin embargo, la primera visita es clave puesto que en esta se discute información básica sobre la hepatitis $\mathrm{C}$ y su tratamiento, se establecen los objetivos de la terapia y se recalca al paciente la importancia de la adherencia al medicamento y al seguimiento. Este proceso permite adaptar las estrategias de manejo según las necesidades específicas del paciente $y$, de este modo, optimizar los resultados del tratamiento.

Temas a tratar:

- Hepatitis C (genotipo del VHC, su asociación con la duración del tratamiento y la probabilidad de lograr la curación, gravedad de la enfermedad, medidas para reducir el riesgo de transmisión).

- Tratamiento (forma de administración y almacenamiento del medicamento, qué hacer en caso de omitir una dosis, interacciones medicamentosas).

- Reacciones adversas al medicamento y su manejo. Se le puede indicar al paciente que tome nota sobre cualquier experiencia incómoda que presente durante el tratamiento y puede recomendarse que adopte, preferiblemente, estrategias no farmacológicas para mejorar la tolerancia. De esta forma, el farmacéutico puede disuadir al paciente de abandonar el tratamiento.

- Cambios en estilos de vida para limitar la progresión de la enfermedad, como evitar el consumo de alcohol.

- Indicaciones de que, en caso de visitar la sala de urgencias o de requerir admisión hospitalaria, deben llevar los medicamentos antivirales, dado que el tratamiento puede no estar disponible en esos establecimientos.

Se recomienda entregar información escrita (física o virtual) y emplear herramientas para mejorar la adherencia terapéutica, como pastilleros, alarmas recordatorias y horarios de medicamentos. Adicionalmente, se pueden emplear recordatorios de reabastecimiento para que los pacientes reclamen oportunamente los medicamentos o para que sean entregados en su domicilio. De igual forma, se pueden generar alarmas en los dispositivos móviles del paciente, para que le recuerden la hora de administración del medicamento.
Farmacovigilancia $(1,8,11,22,29,33,35,36,38,45$, $47,52,53)$

Dado que los $\mathrm{AAD}$ presentan principalmente reacciones adversas al medicamento sintomáticas, la revisión oportuna por parte de los farmacéuticos y la coordinación con los médicos pueden conducir a intervenciones como monitorización, reducción de dosis, cambio o prescripción de medicamentos y recomendación de medidas no farmacológicas para el manejo sintomático, en busca de evitar la interrupción temprana del tratamiento o la falta de adherencia del paciente.

Esta revisión por los farmacéuticos se realiza principalmente durante las visitas de seguimiento o al momento de la dispensación, en las que se realizan preguntas al paciente sobre los efectos adversos comúnmente relacionados con el tratamiento antiviral y se revisan los paraclínicos para monitorizar la presencia de reacciones adversas al medicamento. Posteriormente, las reacciones detectadas se notifican a los sistemas de farmacovigilancia con información completa sobre el medicamento.

De igual forma, se debe incluir dentro del proceso de farmacovigilancia la revisión de reportes de seguridad realizados por los entes regulatorios de medicamentos y notificar a los demás profesionales de la salud.

\section{Investigación (8)}

Es la participación en la realización de ensayos clínicos de nuevos tratamientos y en la creación de literatura científica sobre el uso de medicamentos antivirales en diversas poblaciones de pacientes. El farmacéutico puede colaborar activamente con otros proveedores de atención en salud en varios tipos de investigación, incluidos estudios de efectividad y seguridad, farmacocinética y farmacoeconómicos.

\section{Otros servicios de apoyo}

\section{Desarrollo de sistemas de información y de soporte de decisiones clínicas $(20,33,44,45,54)$}

Es la elaboración de sistemas de información y de soporte de decisiones clínicas que pueden ayudar a promover la calidad y la eficiencia del proceso de atención en salud. Estos pueden ser tan complejos como las instituciones estén dispuestas a desarrollarlos. Los más sencillos podrían ser documentos de orientación clínica en los que se establezcan los criterios de selección de los pacientes para tratamiento, protocolos de manejo para poblaciones especiales (edad avanzada, enfermedad renal crónica, pediátricos, entre otros), detalles del proceso de la atención e indicaciones para el manejo de las interacciones medicamento- 
sas, todo esto de acuerdo con las guías de práctica clínica adoptadas en el país.

Los sistemas más complejos permiten registrar la información clínica de los pacientes desde la historia clínica, medir la adherencia del paciente al tratamiento antiviral e, inclusive, generar eventos y alertas farmacéuticas automáticas en relación con la efectividad y seguridad del tratamiento farmacológico. Estos sistemas pueden facilitar el seguimiento farmacoterapéutico de los pacientes al incorporar automáticamente los análisis hematológicos, bioquímicos y microbiológicos desde las bases de datos del laboratorio, y proporcionar información inmediata para su análisis y tratamiento estadístico.

\section{Participación en un equipo multidisciplinario (33)}

Se trata de la conformación de grupos con diferentes profesionales de la salud, encargados de la atención en salud de los pacientes con hepatitis $C$, en los que se incluye al farmacéutico para discutir casos particulares con el fin de llegar a consensos sobre los tratamientos más idóneos y rentables.

\section{Acompañamiento entre las transiciones de la atención}

$(3,8,33)$

Participación del farmacéutico clínico durante las transiciones del paciente entre instituciones de atención médica (por ejemplo, del hospital a clínicas ambulatorias o viceversa). Los farmacéuticos clínicos tienen la posibilidad de capacitar al personal médico y asistencial sobre la importancia de la continuidad del tratamiento de la hepatitis C, los eventos adversos y las interacciones medicamentosas. Dentro de los procesos que pueden desarrollarse están la conciliación de medicamentos y la coordinación y adquisición de medicamentos.

\section{Grupo de soporte (55)}

Son grupos orientados a ofrecer apoyo a los pacientes con hepatitis $\mathrm{C}$, amigos y familiares. En este grupo se pueden programar sesiones educativas para cada mes del año, en las que se aborden las generalidades de la enfermedad, el tratamiento, reacciones adversas de los medicamentos, nutrición y efectos en el hígado, el impacto emocional del diagnóstico de la hepatitis $\mathrm{C}$, terapias alternativas, acceso a la atención en salud, experiencias personales, entre otras temáticas.

\section{Capacitación para profesionales de la salud $(8,47)$}

Es la capacitación a los profesionales de la salud sobre las complicaciones de la enfermedad, los criterios de tratamiento y el uso adecuado de medicamentos mediante el seguimiento de las guías de práctica clínica. Dependiendo del entorno, estas capacitaciones pueden hacerse presenciales o mediante conferencias virtuales. Esto puede incentivar la creación de paneles de discusión clínica.

\section{Envío de cartas de motivación y correos (56)}

Es una estrategia para incentivar la adherencia al tratamiento a través del envío de cartas de motivación para los pacientes, además de responder a las solicitudes de información realizadas por ellos.

\section{Evaluación de las actividades del servicio farmacéutico en el proceso de atención}

Las funciones de los servicios farmacéuticos se extienden más allá de la prestación de servicios clínicos y deberían incluir procesos orientados a la garantía de la calidad. Es por esto que se requiere de la construcción de indicadores que permitan evaluar los resultados de las actividades realizadas por los profesionales farmacéuticos y el registro de la información de los pacientes que han sido tratados (3).

Dentro de los indicadores que pueden considerarse están las tasas de cumplimiento de los pacientes, patrones de uso, adherencia a guías de tratamiento, efectividad del tratamiento, frecuencia y gravedad de los problemas relacionados con medicamentos y reacciones adversas al medicamento, grado de evitabilidad de los problemas relacionados con medicamentos, costos, satisfacción del paciente, entre otros $(29,44,45,47)$.

Los indicadores de gestión deberían presentarse periódicamente al equipo de trabajo (33) y a los demás profesionales de la salud, empleando presentaciones, transmisiones virtuales en vivo, publicación en la web o distribución por correo electrónico (47).

\section{Evaluación de costos}

La actuación del farmacéutico dentro de la atención a pacientes con hepatitis $C$ juega un papel vital en la contención de costos, principalmente al prevenir gastos médicos innecesarios mediante la optimización de las terapias (8, $44,57)$. Por esta razón, es necesario que participe en el análisis de los costos relacionados con la atención en salud (54), de los costos ahorrados por las intervenciones farmacéuticas $(28,32)$ y del retorno de la inversión $(32)$, dado que esta información ayuda a justificar la implementación o expansión de los servicios de atención farmacéutica (58).

Lavitas y colaboradores analizaron la evitación de costos generada por un programa integral de gestión de medicamentos para el VHC, en una colaboración realizada por los servicios de farmacia clínica de la Universidad de Massachusetts con el programa Medicaid de Massachusetts en los EE.UU. y se encontró que, al optimizar los regímenes de tratamiento, se evitó el gasto de más de 3,7 millones de dólares en pacientes que completaron el tratamiento (32).

Radley y colaboradores compararon los costos de la atención convencional de pacientes con VHC (en hospitales) frente a la atención dirigida por farmacéuticos (en clínicas 
de atención primaria) y se encontró que esta última puede reducir el costo hasta en un $74,4 \%$ ( $£ 933$ frente a $£ 238$ ), debido a que requieren instalaciones menos costosas y la utilización de pruebas y requisitos de monitorización simplificados. Así mismo, un programa integral puede aumentar la cantidad de personas que acceden al tratamiento y acortar el tiempo para que las personas con infección del VHC alcancen la curación (10).

\section{Evaluación de la satisfacción del paciente}

Los servicios farmacéuticos se han implementado en una variedad de entornos; sin embargo, pocos de ellos han evaluado y publicado sobre la satisfacción de los pacientes con respecto a los servicios brindados, especialmente en el área de hepatología (23). Robustillo y colaboradores expresan la necesidad de medir la satisfacción de los pacientes dado que permiten conocer su opinión sobre los servicios y terapias que reciben, considerándolo como una medida de resultado en salud directa (39).

El momento más común para evaluar la satisfacción del paciente ha sido al final del proceso de atención, aunque en algunos estudios, como el realizado por Menchen y colaboradores, se evaluó la variación de la satisfacción con la intervención realizada antes de la implementación del modelo de atención integral a los pacientes con VHC y 6 meses después (59).

Además de la satisfacción con el servicio, puede evaluarse, igualmente, la satisfacción clínica (39). Los principales puntos a evaluar podrían incluir satisfacción con el tratamiento (efectividad, reacciones adversas y los cambios que implica la terapia) (39), satisfacción con la información recibida (recomendaciones de estilos de vida y vacunación, educación en el manejo de la hepatitis $\mathrm{C}$ y su tratamiento) y satisfacción con el servicio (tiempos de espera, accesibilidad del proveedor de servicios de atención en salud, habilidad del proveedor para manejar las preguntas y preocupaciones, referencia a otros servicios en caso de requerirlos) $(23,40,59)$.

\section{Evaluación de conocimientos en VHC}

Para evaluar el efecto de la educación proporcionada por el farmacéutico en el conocimiento del paciente o de los profesionales de la salud, puede realizarse un cuestionario antes y después de la educación que incluye temas como mecanismo de transmisión, tratamiento y reacciones adversas, con el fin de determinar el estado inicial y final de conocimientos sobre el VHC $(7,17)$.

\section{Uso de tecnologías en la práctica farmacéutica}

La inclusión de las tecnologías de la comunicación (TIC) dentro del ejercicio farmacéutico (telefarmacia) ha permitido reducir los tiempos de atención y mejorar el acceso de los pacientes a los proveedores de atención médica
(5), debido a que facilita la educación y el apoyo del personal farmacéutico inclusive fuera del horario de atención (líneas de atención telefónica 24/7), cuando el farmacéutico se encuentra por fuera del sitio de trabajo o cuando los pacientes residen en áreas rurales y es necesario reducir las distancias de viaje $(5,8,22,48,49,56)$.

Así mismo, la telefarmacia permite realizar el seguimiento farmacoterapéutico a pacientes que se encuentran en lugares distantes y no pueden viajar a las clínicas para sus visitas presenciales $(5,22)$, vigilar la aparición de eventos adversos, brindar recomendaciones de medicamentos que no requieren prescripción para su manejo y, de ser necesario, referir a un médico (60). Grisheau y colaboradores describieron un modelo en el que se programaron comunicaciones telefónicas con el paciente a partir de las dos semanas de tratamiento. Las llamadas se realizaban cada cuatro semanas y en ellas se evaluaban los efectos adversos, la adherencia al plan de tratamiento, la necesidad de renovación de prescripciones médicas y se garantizaba el seguimiento de la información clínica del paciente y de los exámenes requeridos. Todas estas llamadas se documentaban en la historia clínica electrónica del paciente y eran enviadas al médico responsable. Es importante resaltar que las llamadas de seguimiento se escalonaban con visitas a la clínica para que los pacientes recibieran, como mínimo, algún tipo de contacto con la clínica cada dos semanas durante el tratamiento (27).

De igual manera, las TIC pueden ser empleadas para recordarle a los pacientes por correo electrónico, mensajes al móvil o llamadas, sobre sus trámites, citas o realización de controles médicos y de laboratorio o para evaluar la calidad de vida relacionada con la hepatitis $\mathrm{C}(25,30)$.

\section{Propuesta de una vía clínica para el manejo de la hepatitis C con participación del farmacéutico}

Para la realización de esta propuesta, en la que se incluye la perspectiva de los servicios farmacéuticos (Figura 2), se partió del manejo propuesto por el Ministerio de Salud y Protección Social de Colombia, para el manejo de la hepatitis C (61). A la propuesta del Ministerio se integró la información obtenida en esta revisión.

Para la aplicación de este modelo, en un contexto particular, debe considerarse la legislación y las actividades autorizadas para los farmacéuticos, los recursos disponibles y el nivel de interconexión entre profesionales de la salud, los ámbitos asistenciales y los diferentes procesos de la atención.

La Figura 2 presenta el diagrama general de atención.

\section{Promoción, prevención, tamización y diagnóstico}

La identificación de las personas infectadas por VHC puede realizarse en tres escenarios: comunitario, ambula- 


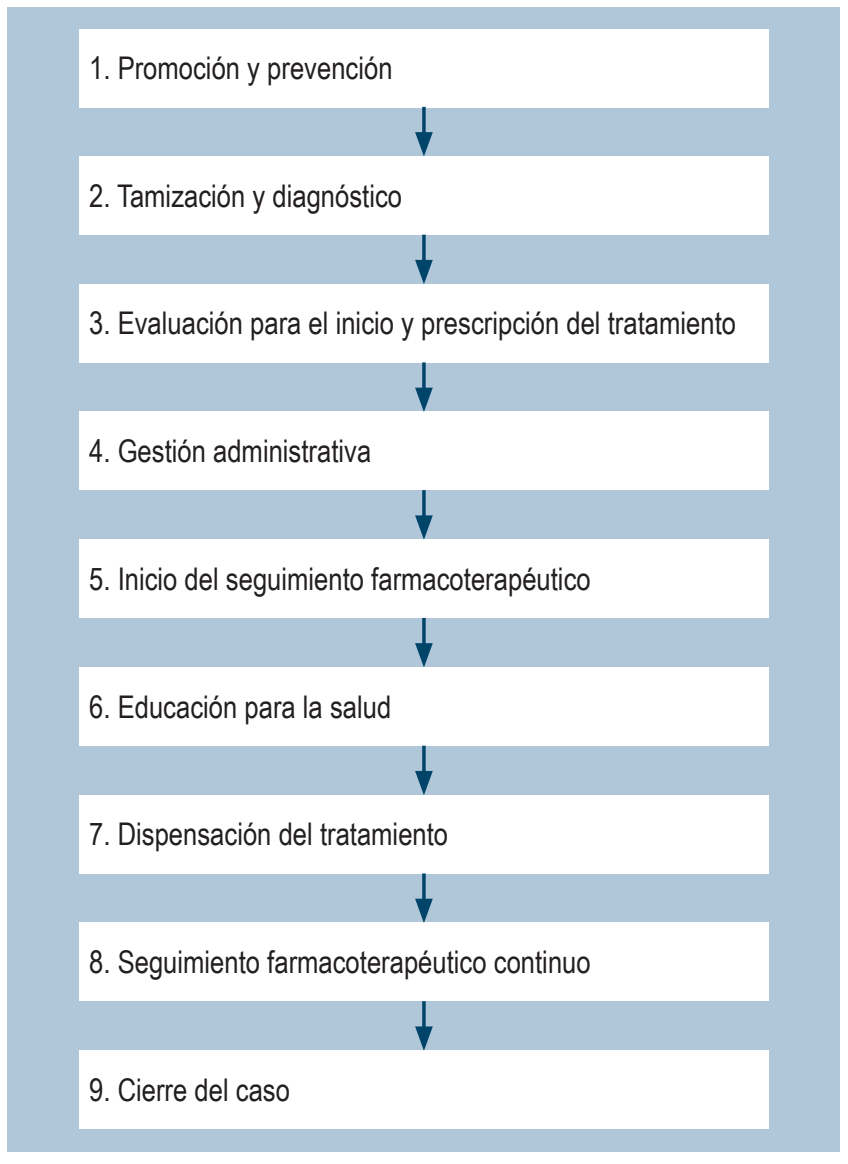

Figura 2. Diagrama general de la propuesta de vía clínica para el manejo de la hepatitis $\mathrm{C}$ con participación del farmacéutico. Adaptado de: Ministerio de Salud y Protección Social - Instituto de Evaluación Tecnológica en Salud. Vía clínica para el tratamiento de hepatitis C. Bogotá, D.C: Ministerio de Salud y Protección Social; 2017.

torio y hospitalario, ya sea por personal farmacéutico o de enfermería (Figura 3). Para iniciar, se sugiere realizar charlas educativas sobre la enfermedad y los factores de riesgo para presentarla. Posteriormente, podría aplicarse una lista de verificación a quienes den su consentimiento, para identificar los comportamientos o factores de riesgo de presentar la infección. A las personas que presenten factores de riesgo, se les puede realizar tamizaje con pruebas rápidas o anticuerpo anti-VHC, según la disponibilidad. Cualquier resultado positivo deberá ser confirmado mediante prueba de ácido ribonucleico (ARN)-VHC.

La participación del farmacéutico comunitario en la detección de pacientes con VHC es crucial, debido a que las personas sin vinculación al sistema de salud y que presentan riesgo de infección por el VHC acuden inicialmente a las farmacias comunitarias para solicitar algún tipo de asistencia. Es por esto que en este nivel debe tenerse disponibilidad de pruebas rápidas de VHC y capacitar al personal farmacéutico en el uso del dispositivo, lo cual podría favorecer la identificación de personas con VHC aún no diagnosticadas (21). De este modo, la farmacia comunitaria puede actuar como nodo de captación de pacientes, especialmente los más vulnerables, como son las personas de escasos recursos y UDI; además de ser un apoyo en la prevención de la enfermedad y su transmisión, y en la vinculación del paciente a la atención en salud.

\section{Evaluación para el inicio y prescripción del tratamiento}

Los pacientes con diagnóstico confirmado de hepatitis C crónica deben ser valorados por personal médico para iniciar el tratamiento. Adicionalmente, se sugiere el apoyo de un equipo multidisciplinario (53), que podría estar constituido por profesionales de medicina, enfermería, trabajo social, psicología y farmacéutica, en busca de evaluar posibles riesgos de no adherencia al tratamiento y reducir, de manera oportuna, cualquier barrera de acceso y alcanzar los objetivos terapéuticos trazados (Figura 4).

\section{Gestión administrativa}

Debido a los altos costos de los $\mathrm{AAD}$, ha sido necesaria la aplicación de estrategias como el proceso de autorización previa, para controlar el gasto dentro de los sistemas de salud. Mediante este proceso, las empresas aseguradoras determinan si el tratamiento es médicamente necesario y adecuado según el diagnóstico y condición del paciente (6). Los farmacéuticos han trabajado en la coordinación de dicho proceso, en la adquisición, dispensación de medicamentos $(2,6,22,23,25-27,36)$, optimización de la terapia y control del gasto (Figura 4) (44).

\section{Seguimiento farmacoterapéutico}

Debido a la reciente comercialización de nuevos $\mathrm{AAD}$, es necesaria la instauración de programas intensivos de seguimiento farmacoterapéutico que permitan la vigilancia de la seguridad y efectividad de estos medicamentos en la práctica clínica (28). Este es un proceso continuo en el que se incluye al farmacéutico dentro del equipo multidisciplinario con el fin de hacer una valoración integral del paciente, de sus enfermedades y terapias, lo que permite la identificación oportuna de problemas relacionados con medicamentos potenciales y reales $(8)$.

El seguimiento farmacoterapéutico comienza antes de que el paciente inicie su tratamiento (Figura 5) y se realiza durante el curso del mismo, e incluye varias actividades: 


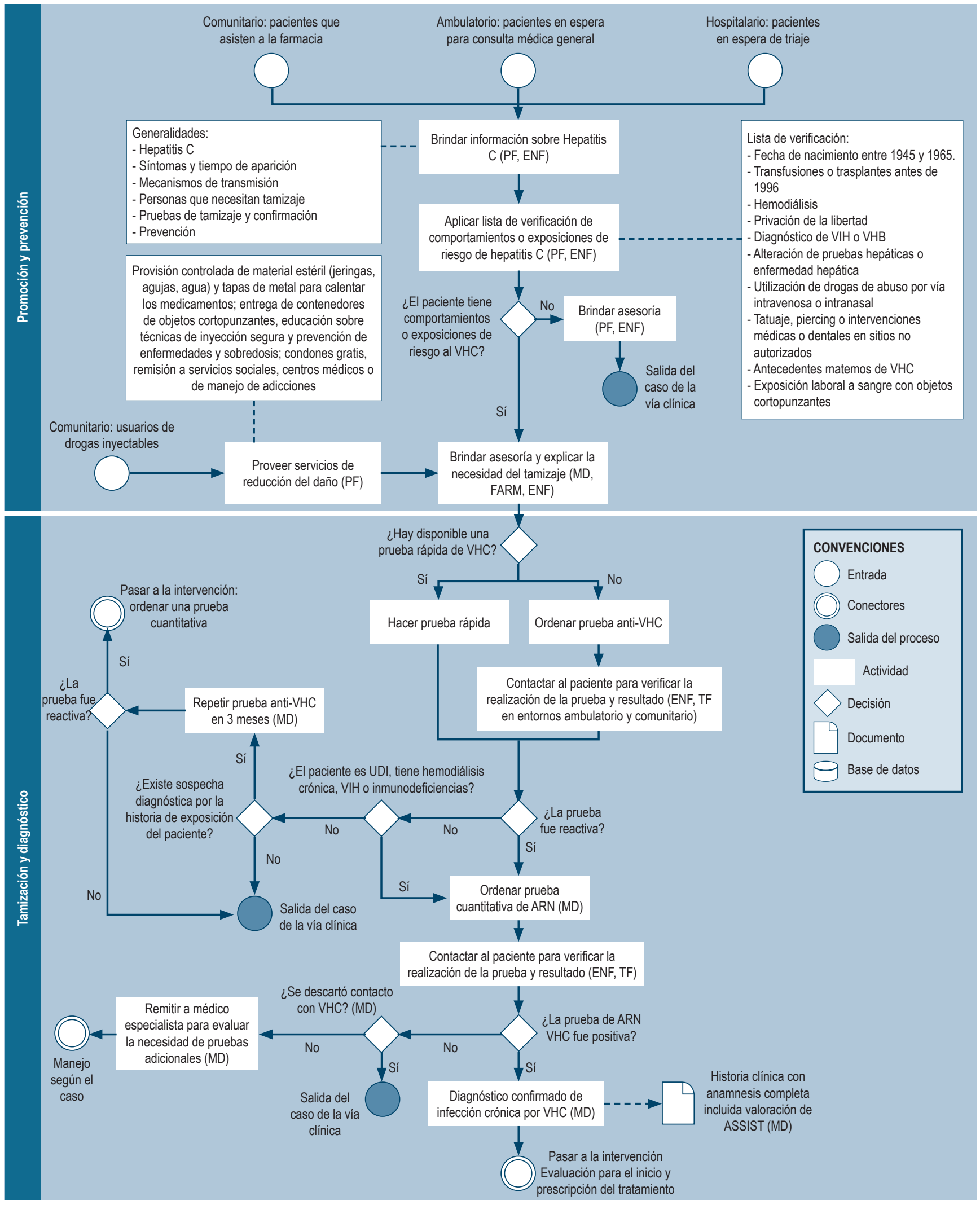

Figura 3. Promoción y prevención farmacéutica, tamización y diagnóstico. ENF: personal de enfermería; FARM: farmacéutico clínico; MD: médico general; PF: personal de farmacia (incluye técnico, profesional o estudiantes de apoyo); TF: técnico de farmacia.; UDI: usuario de drogas inyectables; VHC: virus de la hepatitis C, VIH: virus de la inmunodeficiencia humana. 


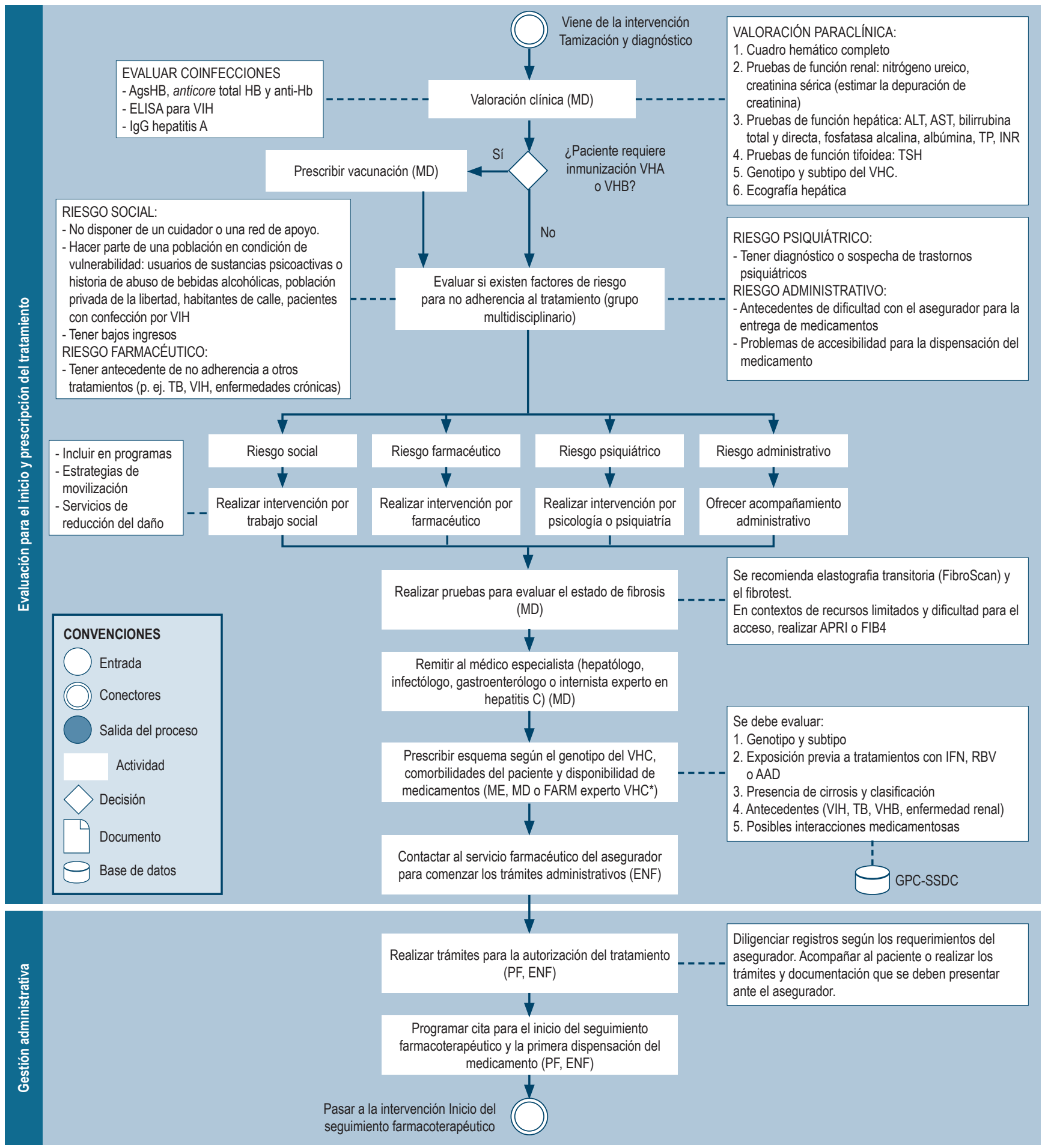

Figura 4. Evaluación para el inicio y prescripción de tratamiento; gestión Administrativa. ${ }^{*}$ Dependiendo del contexto, los médicos generales o farmacéuticos clínicos expertos en hepatitis $\mathrm{C}$ podrían prescribir los $\mathrm{AAD}$, previo consenso con los especialistas y evaluación de los parámetros clínicos, historial médico, comorbilidades y posibles contraindicaciones de la terapia, adhiriéndose a las guías de práctica clínica adoptadas en el país. AgsHB: antígeno de superficie de la hepatitis B; ALT: alanina-aminotransferasa; AST: aspartato-aminotransferasa; ELISA: ensayo por inmunoabsorción ligado a enzimas (por sus siglas en inglés: Enzyme-Linked ImmunoSorbent Assay); ENF: personal de enfermería; FARM: farmacéutico clínico; HB: hepatitis B; Hb: hemoglobina; IFN: interferón; GPC: guía de práctica clínica; INR: índice internacional normalizado; MD: médico general; ME: médico especialista (hepatólogo, gastroenterólogo, infectólogo o internista con experiencia en el manejo de hepatitis C); PF: personal de farmacia (incluye técnico, profesional o estudiantes de apoyo); TP: tiempo de protrombina; RBV: ribavirina; SSDC: sistema de soporte de decisiones clínicas; TB: tuberculosis; TSH: tirotropina; VHB: virus de la hepatitis B; VHC: virus de la hepatitis C. 


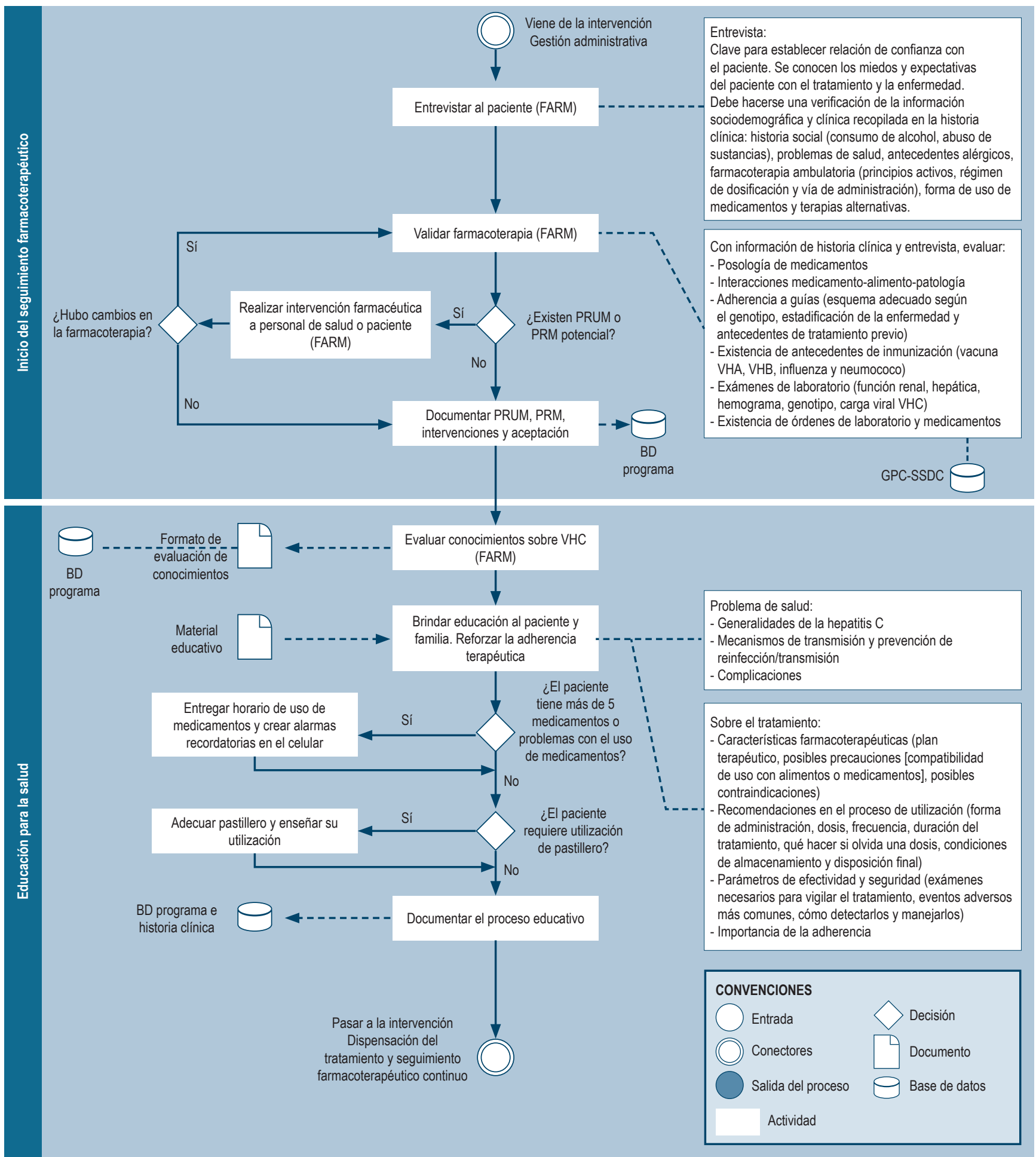

Figura 5. Inicio de seguimiento farmacoterapéutico y educación para la salud. BD: base de datos; FARM: farmacéutico clínico; GPC: guía de práctica clínica; PRUM: problemas relacionados con el uso de medicamentos; PRM: problemas relacionados con medicamentos; SSDC: sistema de soporte de decisiones clínicas. 
- Evaluación inicial por parte del farmacéutico (entrevista farmacéutica): es la primera reunión que tiene el paciente con el farmacéutico, en ella se busca establecer una relación de confianza, construida desde la escucha activa y la empatía. En este primer encuentro se resuelven las dudas del paciente sobre su enfermedad y tratamiento, a partir del reconocimiento de sus expectativas (36).

- Validación de la farmacoterapia: con la información recolectada en la entrevista farmacéutica y en la historia clínica del paciente, el farmacéutico hace una revisión de las prescripciones médicas y verifica su idoneidad y la del esquema antiviral elegido según las guías de práctica clínica (considerando el genotipo, estadificación del estado de cirrosis y antecedentes de tratamiento previo). Adicionalmente, evalúa otras condiciones que puedan contraindicar la terapia $(1,3,8,10,25,27$, $29,30,32,33,35,37,41,42,44-48)$. Debe tenerse en cuenta que en países donde no se cuente con esquemas pangenotípicos, es necesario evaluar el genotipo viral para individualizar la terapia y ofrecer tratamientos costo-efectivos (57). La validación de la farmacoterapia constituye una estrategia para la prevención, identificación y resolución de errores de medicación (28) o de problemas relacionados con medicamentos $(8$, 29 ), entre los que pueden estar la presencia de medicamentos o terapias alternativas que pueden interactuar con el tratamiento antiviral, interacciones fármacoenfermedad, o la necesidad de optimizar el manejo de patologías del paciente diferentes a la hepatitis C (8). En algunos contextos, el farmacéutico debe asegurarse de que los tratamientos prescritos se ajusten a los planes de beneficios farmacéuticos establecidos por la institución o el país, como el caso de la Veterans Health Administration en los EE.UU (3).

\section{Revisión de antecedentes de inmunización}

Es la evaluación los antecedentes de inmunización y de la necesidad de vacunas contra el virus de la hepatitis A y B, influenza y neumococo $(8,48)$.

\section{Verificación de órdenes de laboratorio y medicamentos}

El farmacéutico verifica que hayan sido realizadas adecuadamente las prescripciones de los medicamentos acorde al tiempo de tratamiento, al igual que las órdenes de laboratorio necesarias para el seguimiento (3). En ciertos países, el farmacéutico tiene la autoridad para ordenar o modificar, según el protocolo y con la firma del médico, los medicamentos y las pruebas de laboratorio necesarias para evaluar la seguridad y efectividad de la terapia $(3,34,48)$.

\section{Educación para la salud}

La participación del farmacéutico en la educación para la salud puede solventar la limitada disponibilidad de tiempo de los proveedores médicos para asesorar al paciente sobre el estado de la enfermedad y el uso adecuado de los medicamentos. Esto puede impactar positivamente la adherencia del paciente al tratamiento de la hepatitis $\mathrm{C} y$ aumentar las tasas de curación (8).

Adicional al proceso educativo individual, pueden instaurarse grupos de soporte para ofrecer apoyo a los pacientes con hepatitis C (Tabla 2), que mejoren el conocimiento y la perspectiva de los pacientes sobre su enfermedad, además de mejorar la visibilidad y percepción del papel del farmacéutico como proveedor de atención en salud en la comunidad (55).

\section{Dispensación de medicamentos}

La dispensación de medicamentos puede realizarse durante la consulta de seguimiento farmacoterapéutico con el farmacéutico $(28,29)$, mediante la coordinación con el paciente para que se dispense en la farmacia más cercana $(25,27)$, para que sean enviados a su domicilio $(1,22$, 30) o mediante terapia directamente observada (también conocido como suministro diario supervisado), en la cual los pacientes reciben el tratamiento diario, y para la administración de las dosis de los fines de semana (cuando el mismo paciente debe administrarse el medicamento), el farmacéutico y el paciente pueden elaborar un plan de acción para llevar a cabo esta actividad (31).

La modalidad de dispensación depende de las posibilidades del contexto, los recursos disponibles y las necesidades del paciente. Por esto, se sugiere que se haga una evaluación de la adherencia y de las condiciones sociodemográficas y clínicas del paciente para establecer la forma y periodicidad de dispensación más adecuada (Figura 6).

Para llevar un control de la adherencia, debe hacerse un registro de la dispensación del tratamiento y, en caso de no utilizarse la terapia directamente observada, se sugiere hacer verificación de la toma del medicamento empleando las TIC.

\section{Seguimiento farmacoterapéutico continuo}

Las consultas de seguimiento farmacoterapéutico presenciales pueden realizarse cada 28-30 días y, además de incluir las actividades mencionadas en el inicio del seguimiento farmacoterapéutico (Figura 7), abarca: 


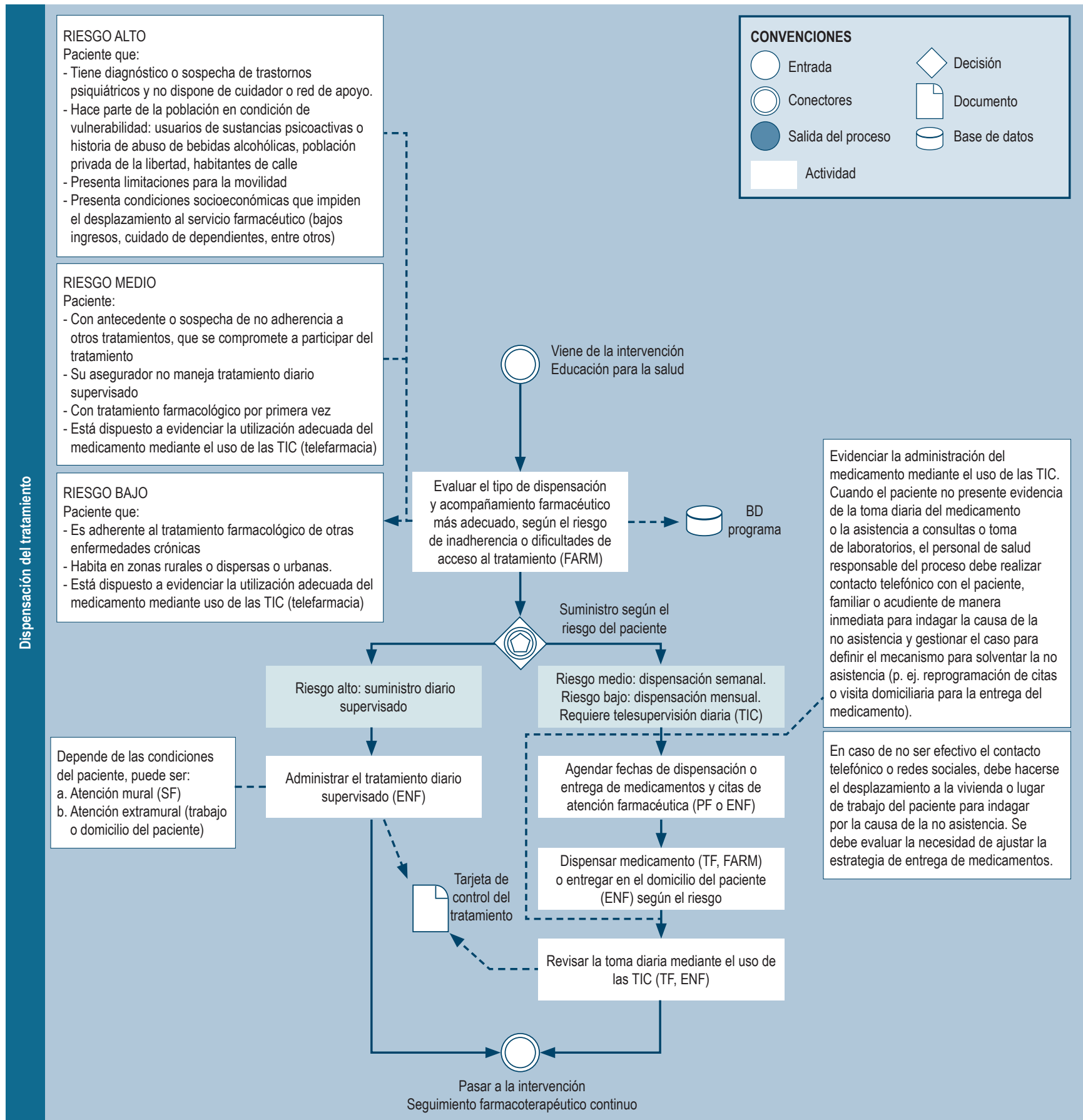

Figura 6. Dispensación del tratamiento. BD: base de datos; ENF: personal de enfermería; FARM: farmacéutico clínico; PF: personal de farmacia (incluye técnico, profesional o estudiantes de apoyo); SF: servicio farmacéutico; SSDC: sistema de soporte de decisiones clínicas; TF: técnico de farmacia; TIC: tecnologías de la información y la comunicación; VHC: virus de la Hepatitis C.

- Verificación de los medicamentos que se han añadido o retirado de la farmacoterapia del paciente (35).

- Evaluación de la efectividad del tratamiento mediante la revisión de resultados de laboratorio como carga viral y pruebas de función hepática.
- Detección, evaluación y notificación de reacciones adversas al medicamento y recomendaciones para su manejo: se evalúa la seguridad del tratamiento mediante la entrevista al paciente y la revisión de paraclínicos (cuadro hemático, pruebas de tiroides [para el 


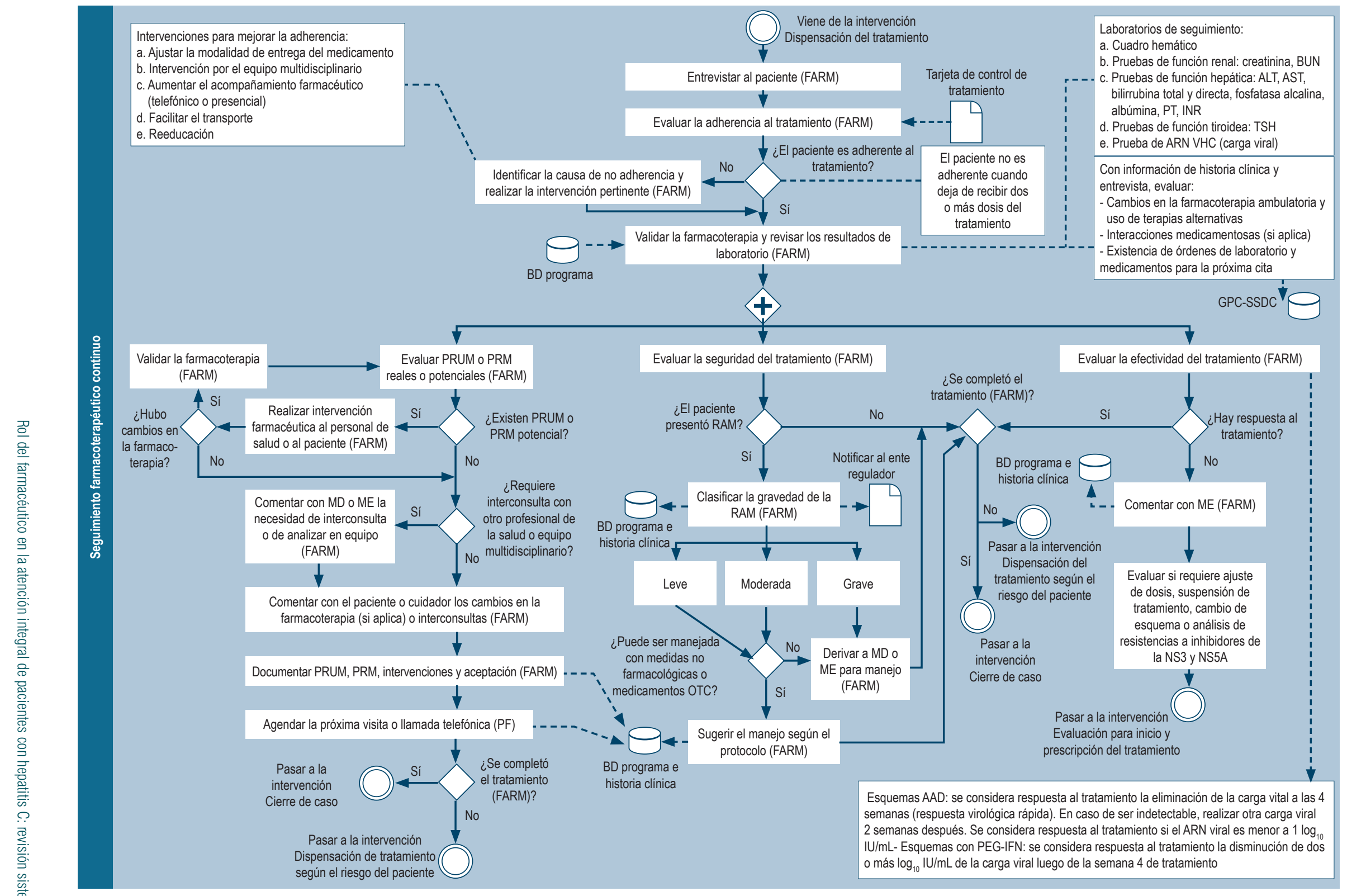

Figura 7. Seguimiento farmacoterapéutico continuo. BD: base de datos; BUN: nitrógeno ureico sanguíneo; FARM: farmacéutico clínico; MD: médico general; ME: médico especialista (hepatólogo, gastroenterólogo, infectólogo o internista con experiencia en el manejo de hepatitis C); NS3: proteína no estructural 3; NS5A: proteína no estructural 5A; OTC: medicamentos de venta libre; PEGIFN: PEG-interferón; PF: personal de farmacia (incluye técnico, profesional o estudiantes de apoyo); PRUM: problemas relacionados con el uso de medicamentos; PRM: problemas relacionados con medicamentos; RAM: reacción adversa al medicamento; SSDC: sistema de soporte de decisiones clínicas. 
caso de terapias con ribavirina o interferón] y función renal) $(8,19,22,30,35,36,42,47)$.

- Evaluación de la adherencia del paciente: con preguntas sobre la utilización del medicamento (36), inspección de empaques de las tabletas dispensadas al paciente (49), análisis de fechas de dispensación del medicamento registradas en los sistemas de información $(1,8,23,33$, $41,44,47)$ y los registros de toma del medicamento (10). También pueden aplicarse cuestionarios para la medición de adherencia como el Morisky-Green (40, 43), el Haynes-Sackett (38) o una escala visual análoga (EVA) en la que el paciente valore su nivel de cumplimiento (40).

- Acompañamiento entre las transiciones: en caso de que el paciente deba ser atendido a nivel hospitalario, sea para el manejo de una reacción adversa o de complicaciones por sus patologías, el farmacéutico debe brindar apoyo para garantizar la conciliación de los medicamentos y la continuidad de la terapia en ese escenario.

\section{Intervención farmacéutica}

Durante toda la práctica farmacéutica pueden detectarse errores de medicación o problemas relacionados con medicamentos reales o potenciales, o puede ser necesario optimizar la terapia del paciente, lo que conduce a intervenciones al personal médico o de enfermería, o al paciente, según sea el caso (Tabla 3) $(1,3,8,19,22,23,28-34,37,41,42$, $45,58,60)$. Se recomienda que todas las intervenciones y recomendaciones realizadas por el farmacéutico, incluidas las visitas, llamadas, la revisión de la farmacoterapia y todas las actividades relacionadas con el asesoramiento y la adherencia del paciente, queden registradas en la historia clínica o en los sistemas de información $(8,60)$.

Tabla 3. Tipos de intervenciones farmacéuticas

\begin{tabular}{|c|c|}
\hline $\begin{array}{l}\text { Orientada a la estrategia } \\
\text { farmacológica o cantidad } \\
\text { del medicamento }\end{array}$ & $\begin{array}{l}\text { Brindar recomendaciones sobre } \\
\text { ajustes en la terapia y dosificación }\end{array}$ \\
\hline $\begin{array}{l}\text { Orientada a la } \\
\text { monitorización del } \\
\text { tratamiento }\end{array}$ & $\begin{array}{l}\text { Recomendaciones sobre la } \\
\text { prescripción o modificación de } \\
\text { órdenes de laboratorio }\end{array}$ \\
\hline $\begin{array}{l}\text { Orientada al proceso de } \\
\text { atención en salud }\end{array}$ & $\begin{array}{l}\text { Derivar a médicos especialistas u } \\
\text { otros servicios } \\
\text { Renovar las prescripciones de } \\
\text { medicamentos } \\
\text { Ordenar vacunación } \\
\text { Modificar la forma de administración }\end{array}$ \\
\hline $\begin{array}{l}\text { Orientada a la educación } \\
\text { al paciente }\end{array}$ & $\begin{array}{l}\text { Promover la adherencia (disminuir el } \\
\text { incumplimiento voluntario al modificar } \\
\text { actitudes respecto al tratamiento) }\end{array}$ \\
\hline
\end{tabular}

\section{Cierre del caso}

El cierre del caso se presenta cuando el paciente terminó el tratamiento y alcanzó la curación (respuesta virológica sostenida: carga viral indetectable 12 semanas después del fin del tratamiento), por fallecimiento del paciente o cuando el paciente decide no continuar con la terapia (Figura 8). Se sugiere realizar una consulta de seguimiento entre los 6 y 12 meses siguientes al alcance de la respuesta virológica sostenida, especialmente en la población susceptible de reinfección (UDI, personas que viven con VIH, hombres que tienen sexo con hombres, pacientes en hemodiálisis, trabajadores sexuales). Adicionalmente, los pacientes con cirrosis en estadios avanzados o hepatocarcinoma deben continuar con el seguimiento habitual por el médico especialista (hepatólogo o gastroenterólogo). Al finalizar el proceso de atención, se debe evaluar la calidad de la atención prestada mediante la aplicación de cuestionarios de satisfacción.

\section{DISCUSIÓN}

La participación de los servicios farmacéuticos en la atención de los pacientes con hepatitis $\mathrm{C}$, además de promover la adherencia y de mejorar los resultados clínicos, puede reducir los costos del tratamiento al favorecer la optimización de la terapia (44). Su actuación en entornos ambulatorios, comunitarios y hospitalarios, además de ser importante para la población afiliada a los sistemas de salud, es crucial para las personas que habitualmente no utilizan el sistema de atención en salud, ya sea por su condición de vulnerabilidad o por su no afiliación, dado que son ellos quienes suelen recurrir a este tipo de servicios farmacéuticos para tener algún tipo de asistencia. En este sentido, la aplicación de las prácticas identificadas en esta revisión podría ampliar la cobertura de atención a la población afiliada y promover el diagnóstico y tratamiento oportuno en población vulnerable y en personas no afiliadas al sistema de salud. Adicionalmente, una prestación integral del servicio de atención en salud fortalece la colaboración entre el farmacéutico y todos los profesionales de la salud, lo que permitiría evaluar la seguridad de los AAD.

De acuerdo con lo anterior, se presenta una vía clínica para el manejo de la hepatitis $\mathrm{C}$ complementada con las acciones/intervenciones de los servicios farmacéuticos. Esta vía podría adaptarse para su aplicación, según el contexto de cada país, la normatividad vigente, los recursos disponibles y el nivel de interconexión entre profesionales de la salud y los ámbitos asistenciales. De igual forma, podría aplicarse en otras enfermedades de transmisión sexual y enfermedades crónicas de alto costo. 


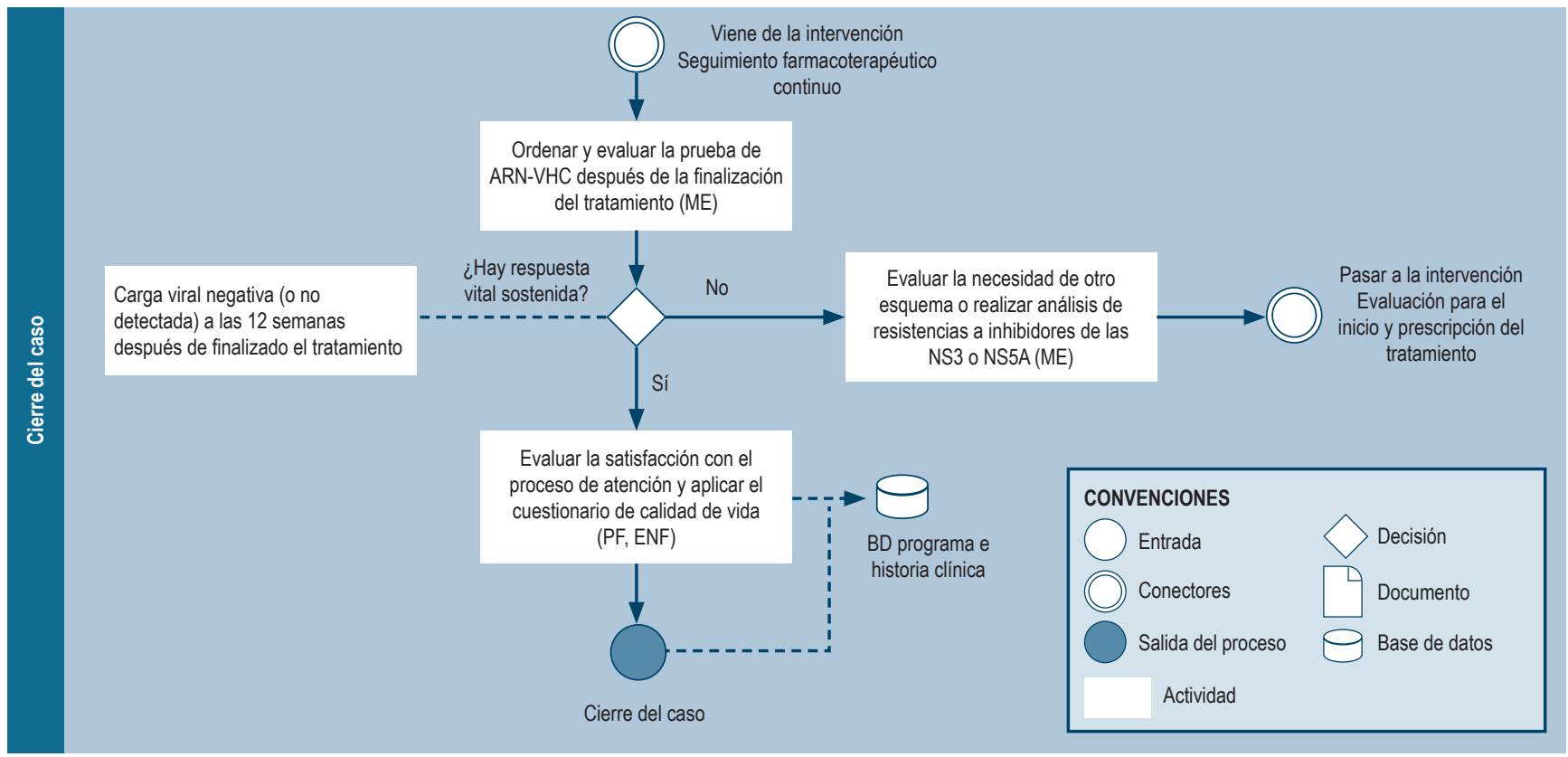

Figura 8. Cierre del caso. ARN: ácido ribonucleico; BD: base de datos; ENF: personal de enfermería; ME: médico especialista (hepatólogo, gastroenterólogo, infectólogo o internista con experiencia en el manejo de hepatitis C); PF: personal de farmacia (incluye técnico, profesional o estudiantes de apoyo); VHC: virus de la hepatitis C.

\section{Hallazgos más relevantes}

Esta revisión permitió identificar las actividades realizadas desde los servicios farmacéuticos en el manejo de la hepatitis $\mathrm{C}$ y, de este modo, proponer una vía clínica para el manejo de la hepatitis $\mathrm{C}$, complementada con las acciones/intervenciones de los servicios farmacéuticos. Es de notar la actuación del personal farmacéutico en cada una de las etapas del proceso de atención, en la que se amplía su rol más allá del seguimiento farmacoterapéutico y participa activamente en procesos claves como el tamizaje del VHC y la vinculación de los pacientes al tratamiento. Respecto a esto, Radley y colaboradores y Dong y colaboradores resaltaron el rol de las farmacias comunitarias y programas de sustitución de opioides como lugares potenciales para implementar pruebas de tamizaje del VHC, especialmente para las personas que no están vinculadas a la atención en salud, para favorecer la detección oportuna del VHC y gestionar un inicio oportuno del tratamiento $(9,10)$. De igual manera, resulta relevante la provisión de servicios de reducción del daño para prevenir la transmisión del VIH y VHC, especialmente en poblaciones de riesgo como los UDI $(9,12-16)$.

De manera particular, en el contexto colombiano y latinoamericano, podría considerarse la participación del farmacéutico en las actividades de promoción y prevención. Esto requiere de un plan estructurado de capacitación para mejorar la aceptabilidad y favorecer las actitudes positivas entre el personal de la farmacia para impulsar estos servicios $(9,12)$. Adicionalmente, es necesario el establecimiento de relaciones públicas y estrategias de mercadeo para aumentar la visibilidad del farmacéutico comunitario (farmacias y droguerías) en este rol ampliado de atención al paciente y determinar un modelo para obtener el reembolso por su actividad y por los servicios ofrecidos en el punto de atención (9).

Otro proceso a considerar es la prescripción, en la cual el farmacéutico no ha tenido mayor injerencia. Sin embargo, los $\mathrm{AAD}$ representan esquemas más sencillos de utilizar, por lo que podría considerarse, tal y como lo manifiestan Galewitz y colaboradores (4) y Radley y colaboradores (10), la posibilidad de que los farmacéuticos clínicos expertos en hepatitis $\mathrm{C}$ prescriban estos antivirales (previo consenso con los especialistas, revisión de guías de práctica clínica y evaluación de los parámetros clínicos, historial médico, comorbilidades y posibles contraindicaciones de la terapia).

Así mismo, la atención farmacéutica puede servir de apoyo en la atención primaria en salud al disminuir los tiempos de espera de los pacientes para ver a un médico. Por ejemplo, en los EE.UU., la formación de los farmacéuticos clínicos y la experiencia en el manejo de hepatitis $\mathrm{C}$ les ha permitido prescribir medicamentos, solicitar análisis de laboratorio, derivar a especialistas y hacer exámenes físicos (4), por lo que se consulta al médico especialista 
únicamente cuando sea necesario. Con este tipo de ajustes, podría liberarse tiempo de los médicos especialistas para ampliar la cobertura de atención a más pacientes crónicos o concentrarse en pacientes con necesidades más complejas.

De igual manera, se destaca la educación al paciente realizada por el farmacéutico o el equipo multidisciplinario como una de las actividades más relevantes para favorecer el empoderamiento de los pacientes y su familia, promoviendo la participación activa en la toma de decisiones relacionadas con su salud $(8,34)$.

Además, se identificó que la utilización de las TIC en la práctica farmacéutica puede ayudar a mejorar el acceso a la atención en pacientes con hepatitis $\mathrm{C}$ y otras enfermedades crónicas (5).

\section{Comparación con publicaciones similares y diferencias con las mismas}

Durante la búsqueda no se encontraron revisiones sistemáticas que respondieran a nuestro objetivo. Editoriales como la realizada por Briggs (20) resumen la participación del personal farmacéutico en el manejo de la hepatitis C; sin embargo, solamente hace alusión a los procesos, sin detallar las actividades que implican y los tiempos para efectuarlas. Por su parte, la Joint Opinion of the GI/Liver/Nutrition and Infectious Diseases Practice and Research Networks del American College of Clinical Pharmacy (8) detalla cada uno de los roles en los que puede participar el farmacéutico clínico, pero no menciona las actividades que pueden ser soportadas por otro personal del servicio farmacéutico como el técnico de farmacia o los estudiantes de apoyo. La presente revisión, además de resumir y describir cada una de las actividades encontradas y el entorno en el que son ejecutadas, realiza una propuesta de vía clínica en la cual se incluye al personal farmacéutico (profesionales, técnico y personal de apoyo) dentro del proceso de atención y su interrelación con otros profesionales de la salud.

El marco normativo colombiano vigente limita algunas de las intervenciones identificadas en esta revisión, en especial las relacionadas con la toma de decisiones sobre tratamientos y sus modificaciones, o referenciación de pacientes a vacunar para otras hepatitis. Por ello, es clave generar evidencia del efecto de este tipo de intervenciones en colaboración con el equipo de atención en salud de este grupo de pacientes, en especial con los médicos tratantes. En este sentido, Briggs (20) establece que es necesario visibilizar el rol del personal farmacéutico como proveedor de atención en salud, especialmente a los encargados de la formulación de políticas públicas, para que los reconozcan como actores claves dentro del equipo asistencial, dado que pueden contribuir a atender y satisfacer las necesidades en salud de los pacientes y de la comunidad.

\section{Limitaciones de la revisión}

Para la inclusión de los artículos en la revisión no se consideró la evaluación de la calidad de los estudios, debido a que el objetivo principal fue identificar todas las acciones e intervenciones realizadas por los servicios farmacéuticos en pacientes con hepatitis $\mathrm{C}$ y los contextos en los que eran aplicadas.

\section{Indicaciones y directrices para futuras investigaciones}

Es necesaria la realización de estudios de la vida real que permitan generar evidencia objetiva de los efectos de la vía clínica propuesta en esta revisión, en la mejora del acceso al tratamiento, en los resultados clínicos y en los costos asociados al proceso de atención en salud.

\section{Agradecimientos}

Al grupo de investigación Promoción y Prevención Farmacéutica de la Universidad de Antioquia (Medellín, Colombia) por el soporte científico y metodológico en el desarrollo de esta revisión.

\section{Fuentes de financiación}

Esta investigación cuenta con financiación del Comité para el Desarrollo de la Investigación de la Universidad de Antioquia (Proyecto CODI 2017-16258). El grupo de investigación recibió recursos por la estrategia de sostenibilidad del Comité para el Desarrollo de la Investigación de la Universidad de Antioquia, 2018-2019.

\section{REFERENCIAS}

1. Tran AN, Sachdev R, Fricker ZP, Leber M, Zahorian T, Shah B, Nunes DP, Long MT. Intensive Pharmacy Care Improves Outcomes of Hepatitis C Treatment in a Vulnerable Patient Population at a Safety-Net Hospital. Dig
Dis Sci. 2018;63(12):3241-9.

https://doi.org/10.1007/s10620-018-5231-0

2. Andres J, Lott S, Qureshi K. Eight-Week Outcomes of Ledipasvir/Sofosbuvir in Noncirrhotic Treatment-Naive Patients with Hepatitis C: Analysis of Pharmacy-Based 
Data. J Manag Care Spec Pharm. 2018;24(1):23-8. https://doi.org/10.18553/jmcp.2018.24.1.23

3. Gauthier TP, Moreira E, Chan C, Cabrera A, Toro M, Carrasquillo MZ, Corentin M, Sherman EM. Pharmacist engagement within a hepatitis $\mathrm{C}$ ambulatory care clinic in the era of a treatment revolution. J Am Pharm Assoc JAPhA. 2016;56(6):670-6. https://doi.org/10.1016/j.japh.2016.06.013

4. Galewitz P. VA Shifts To Clinical Pharmacists To Help Ease Patients' Long Waits [Internet]. Kaiser Health News; 2016 [citado el 28 de abril de 2018]. Disponible en: https:// $\mathrm{khn}$.org/news/va-treats-patients-impatience-with-clinicalpharmacists/

5. You A, Kawamoto J, Smith JP. A pharmacist-managed telemedicine clinic for hepatitis $\mathrm{C}$ care: a descriptive analysis. J Telemed Telecare. 2014;20(2):99-101. https://doi.org/10.1177/1357633X13519043

6. Dunn EE, Vranek K, Hynicka LM, Gripshover J, Potosky D, Mattingly TJ. Evaluating a Collaborative Approach to Improve Prior Authorization Efficiency in the Treatment of Hepatitis C Virus. Qual Manag Health Care. 2017;26(3):136-9.

https://doi.org/10.1097/QMH.0000000000000137

7. Calderon Y, Cowan E, Schramm C, Stern S, Brusalis C, Iscoe M, Rahman S, Verma R, Leider J. HCV and HBV testing acceptability and knowledge among urban emergency department patients and pharmacy clients. Prev Med. 2014;61:29-33.

https://doi.org/10.1016/j.ypmed.2013.12.026

8. Mohammad RA, Bulloch MN, Chan J, Deming P, Love B, Smith L, Dong BJ, GI Liver Nutrition and Infectious Diseases Practice and Research Networks of the American College of Clinical Pharmacy. Provision of clinical pharmacist services for individuals with chronic hepatitis $\mathrm{C}$ viral infection: Joint Opinion of the GI/Liver/Nutrition and Infectious Diseases Practice and Research Networks of the American College of Clinical Pharmacy. Pharmacotherapy. 2014;34(12):1341-54. https://doi.org/10.1002/phar.1512

9. Dong BJ, Lopez M, Cocohoba J. Pharmacists performing hepatitis $\mathrm{C}$ antibody point-of-care screening in a community pharmacy: A pilot project. J Am Pharm Assoc JAPhA. 2017;57(4):510-515.e2. https://doi.org/10.1016/j.japh.2017.04.463

10. Radley A, Tait J, Dillon JF. DOT-C: A cluster randomised feasibility trial evaluating directly observed anti-HCV therapy in a population receiving opioid substitute therapy from community pharmacy. Int J Drug Policy. 2017;47:126-36. https://doi.org/10.1016/j.drugpo.2017.05.042

11. Iizuka T, Eguchi Y, Akase T, Ishizuka H, Yoshiyama Y. Primary Care Enlightenment to Local Inhabitants -Cooperation of Medical Institution and Community Pharmacy in Treatment of Chronic Hepatitis C. Yakugaku Zasshi. 2010;130(12):1633-9. https://doi.org/10.1248/yakushi.130.1633
12. Cooper EN, Dodson C, Stopka TJ, Riley ED, Garfein RS, Bluthenthal RN. Pharmacy participation in nonprescription syringe sales in Los Angeles and San Francisco counties, 2007. J Urban Health Bull N Y Acad Med. 2010;87(4):543-52. https://doi.org/10.1007/s11524-010-9483-z

13. Garfein RS, Stopka TJ, Pavlinac PB, Ross A, Haye BK, Riley ED, Bluthenthal RN. Three years after legalization of nonprescription pharmacy syringe sales in California: where are we now? J Urban Health Bull N Y Acad Med. 2010;87(4):576-85. https://doi.org/10.1007/s11524-010-9463-3

14. Stancliff S, Agins B, Rich JD, Burris S. Syringe access for the prevention of blood borne infections among injection drug users. BMC Public Health. 2003;3:37. https://doi.org/10.1186/1471-2458-3-37

15. Yang Y, Latkin CA, Luan R, Yang C. A cross-sectional study of the feasibility of pharmacy-delivered harm reduction services among people who inject drugs in Xichang, China. BMC Public Health. 2015; 15:885. https://doi.org/10.1186/s12889-015-2236-x

16. Oramasionwu CU, Johnson TL, Zule WA, Carda-Auten J, Golin CE. Using Pharmacies in a Structural Intervention to Distribute Low Dead Space Syringes to Reduce HIV and HCV Transmission in People Who Inject Drugs. Am J Public Health. 2015;105(6):1066-71. https://doi.org/10.2105/AJPH.2015.302581

17. Isho NY, Kachlic MD, Marcelo JC, Martin MT. Pharmacistinitiated hepatitis $\mathrm{C}$ virus screening in a community pharmacy to increase awareness and link to care at the medical center. J Am Pharm Assoc JAPhA. 2017;57(3S):S259-64. https://doi.org/10.1016/j.japh.2017.03.006

18. Pharmacy hepatitis project results positive. The Pharmaceutical Journal. 15 de enero de 2010; News \& analysis: 35 .

19. Showande S, Olaifa A. Community pharmacists 'involvement in the ordering and interpretation of laboratory tests. Int J Pharm Sci Res. 2013;4(3):988-96.

20. Briggs AL. Pharmacists' increasing involvement in hepatitis C management and prevention. J Am Pharm Assoc JAPhA. 2018;58(1):5-6. https://doi.org/10.1016/j.japh.2017.12.008

21. D’Angelo RG, Klepser M, Woodfield R, Patel H. Hepatitis C Virus Screening: A Review of the OraQuick Hepatitis C Virus Rapid Antibody Test. J Pharm Technol. 2015;31(1):13-9. https://doi.org/10.1177/8755122514548228

22. Cohen SM, Kwasny MJ, Ahn J. Use of specialty care versus standard retail pharmacies for treatment of hepatitis C. Ann Pharmacother. 2009;43(2):202-9. https://doi.org/10.1345/aph.1L227

23. Martin MT, Faber DM. Patient satisfaction with the clinical pharmacist and prescribers during hepatitis $C$ virus management. J Clin Pharm Ther. 2016;41(6):645-9. https://doi.org/10.1111/jcpt.12436 
24. Pham TT, Keast SL, Farmer KC, Thompson DM, Rathbun RC, Nesser NJ, Holderread BP, Skrepnek GH. Sustained Virologic Response and Costs Associated with DirectActing Antivirals for Chronic Hepatitis C Infection in Oklahoma Medicaid. J Manag Care Spec Pharm. 2018;24(7):664-76. https://doi.org/10.18553/jmcp.2018.24.7.664

25. Martin MT, Telebak E, Taylor PA, Volozhina O. Development of a specialty medication prior-authorization service at an urban academic medical center. Am J Health Syst Pharm. 2016;73(15):1174-9. https://doi.org/10.2146/ajhp160059

26. Vu TM, Toribio W, Riazi F, Ciprian G, Gibbs N, Giardina M, Camacho JA, Parrella K, Cambe J, Amory C, Chasan R, Sigel KM, Weiss JJ. Increasing Access to Hepatitis C Virus Medications: A Program Model Using Patient Navigators and Specialty Pharmacy to Obtain Prior Authorization Approval. J Manag Care Spec Pharm. 2018;24(4):329-33. https://doi.org/10.18553/jmcp.2018.24.4.329

27. Grischeau M, Zenner J. Optimizing workflow at a multidisciplinary clinic for management of hepatitis $\mathrm{C}$ virus infection. Am J Health-Syst Pharm AJHP Off J Am Soc Health-Syst Pharm. 2012;69(24):2131-3. https://doi.org/10.2146/ajhp120264

28. Ribed A, Rodriguez-González C, Collado-Borrell R, Camino S, Elena L, Alvaro G, Ibañez-García S, TovarPozo M, Herranz-Alonso AM, Sanjurjo-Sáez M. CP-102 Pharmaceutical care monitoring of hepatitis $\mathrm{C}$ outpatients: Guaranteeing safety and efficiency. Eur J Hosp Pharm. 2016;23(Suppl 1):A44.3-A45. https://doi.org/10.1136/ejhpharm-2016-000875.102

29. Márquez-Peiró JF, Pérez-Peiró C, Carmena-Carmena J, Jiménez-Torres NV. Identifying improvement opportunities in the management of hepatitis C. Farm Hosp. 2006;30(3):154-60. https://doi.org/10.1016/S1130-6343(06)73966-6

30. Henderson RR, Visaria J, Bridges GG, Dorholt M, Levin RJ, Frazee SG. Impact of specialty pharmacy on telaprevircontaining 3-drug hepatitis $\mathrm{C}$ regimen persistence. J Manag Care Spec Pharm. 2014;20(12):1227-34. https://doi.org/10.18553/jmcp.2014.20.12.1227

31. Foisy MM, Akai PS. Pharmaceutical care for HIV patients on directly observed therapy. Ann Pharmacother. 2004;38(4):550-6. https://doi.org/10.1345/aph.1D444

32. Lavitas P, Tesell M, Hydery T, Greenwood BC, Price M, Lenz K, Jeffrey P. Overview of Comprehensive Hepatitis C Virus Medication Management in a State Medicaid Program. J Manag Care Spec Pharm. 2016;22(10):1161-6. https://doi.org/10.18553/jmcp.2016.22.10.1161

33. Chamorro-de-Vega E, Rodriguez-Gonzalez CG, GimenezManzorro A, de Lorenzo-Pinto A, Iglesias-Peinado I, Herranz A, Sanjurjo M; GRUviC Study Group. Improving pharmacotherapy outcomes in patients with hepatitis C virus infection treated with direct-acting antivirals: The
GRUviC project. Int J Clin Pract. 2017;71(8):e12988. https://doi.org/10.1111/ijcp.12988

34. Kolor B. Patient education and treatment strategies implemented at a pharmacist-managed hepatitis $\mathrm{C}$ virus clinic. Pharmacotherapy. 2005;25(9):1230-41. https://doi.org/10.1592/phco.2005.25.9.1230

35. Zaepfel M, Cristofaro L, Trawinski A, McCarthy K, Rightmier E, Khadem T. Evaluation of a Hepatitis C Patient Management Program at a University Specialty Pharmacy. Ann Pharmacother. 2017;51(4):307-14. https://doi.org/10.1177/1060028016683495

36. Gomes LO, Teixeira MR, Rosa JAD, Foppa AA, Rover MRM, Farias MR. The benefits of a public pharmacist service in chronic hepattis $\mathrm{C}$ treatment: The real-life results of sofosbuvir-based therapy. Res Social Adm Pharm. 2020;16(1):48-53. https://doi.org/10.1016/j.sapharm.2019.02.008

37. Collado-Borrell R, Lallana-Sainz E, Gimenez-Manzorro A, Ribed-Sanchez A, Lorenzo-Pinto AD, Chamorro E, Romero-Jimenez R, Tovar-Pozo M, Herranz-Alonso A, Sanjurjo-Saez M. PS-020 Drug interactions of new direct acting antiviral agents detected in an intensive pharmaceutical care programme of hepatits $\mathrm{C}$ patients. Eur J Hosp Pharm. 2016;23(Suppl 1):A222-3. https://doi.org/10.1136/ejhpharm-2016-000875.505

38. Masip M, Tuneu L, Pagès N, Torras X, Gallego A, Guardiola JM, Faus MJ, Mangues MA. Prevalence and detection of neuropsychiatric adverse effects during hepatitis C treatment. Int J Clin Pharm. 2015;37(6):1143-51. https://doi.org/10.1007/s11096-015-0177-1

39. Robustillo M de las A, Almeida-Gonzalez CV, MorilloVerdugo R. Relación entre la complejidad farmacoterapéutica y la satisfacción del paciente con el tratamiento. Farm Hosp. 2017; (4):470-8.

40. Cañamares Orbis I, Saez de la Fuente J, Izquierdo García E, Esteban Alba C, Such Díaz A, Escobar Rodriguez I. Experiencia autorreferida en pacientes tratados con antivirales directos frente al virus de la. Farm Hosp. 2016; (6):569-78.

41. Rodríguez-Camacho JM, Vela VV, Fernández MJH, Martín MVM, Bautista MJM, Gil LO. Monitoring of Pharmaceutical Care Hepatitis C program (2007-2011). Eur J Hosp Pharm. 2012;19(2):133.1-133. https://doi.org/10.1136/ejhpharm-2012-000074.127

42. García-Pelayo M, Montilla E, Fuentes B. CP-079 Pharmaceutical Care for patients with hepatitis $\mathrm{C}$ treated with telaprevir. Role in the Regional Hospital. Eur J Hosp Pharm. 2014;21(Suppl 1):A32.3-A33. https://doi.org/10.1136/ejhpharm-2013-000436.78

43. 44th ESCP International Symposium on Clinical Pharmacy Medicines Information: Making Better Decisions: Lisbon, Portugal, 28-30 October 2015. Int J Clin Pharm. 2016;38(2):470-598. https://doi.org/10.1007/s11096-015-0240-y

44. Yang S, Britt RB, Hashem MG, Brown JN. Outcomes of Pharmacy-Led Hepatitis C Direct-Acting Antiviral 
Utilization Management at a Veterans Affairs Medical Center. J Manag Care Spec Pharm. 2017;23(3):364-9. https://doi.org/10.18553/jmcp.2017.23.3.364

45. Margusino-Framiñán L, Cid-Silva P, Mena-de-Cea Á, Sanclaudio-Luhía AI, Castro-Castro JA, Vázquez-González G, Martín-Herranz I. Intelligent MONitoring System for antiviral pharmacotherapy in patients with chronic hepatitis C (SiMON-VC). Farm Hosp. 2017;41(n01):68-88. https://doi.org/10.7399/fh.2017.41.1.10590

46. Sebhatu P, Martin MT. Genotype 1 hepatitis $C$ virus and the pharmacist's role in treatment. Am J Health Syst Pharm. 2016;73(11):764-74. https://doi.org/10.2146/ajhp150704

47. Belperio PS, Backus LI, Ross D, Neuhauser MM, Mole LA. A Population Approach to Disease Management: Hepatitis C Direct-Acting Antiviral Use in a Large Health Care System. J Manag Care Pharm. 2014;20(6):533-40. https://doi.org/10.18553/jmcp.2014.20.6.533

48. Walters-Smith N, Marshall SM. Opportunities and considerations for pharmacist intervention in the management of the chronic hepatitis $\mathrm{C}$ patient. J Manag Care Pharm JMCP. 2009; 15(5):417-9. https://doi.org/10.18553/jmcp.2009.15.5.417

49. Marino EL, Alvarez-Rubio L, Miro S, Modamio P, Banos F, Lastra CF, Alberdi-Leniz A. Pharmacist intervention in treatment of patients with genotype 1 chronic hepatitis C.J Manag Care Pharm JMCP. 2009;15(2):147-50. https://doi.org/10.18553/jmcp.2009.15.2.147

50. Yeste-Gómez I, Rodríguez-González CG, GiménezManzorro Á, Ais-Larisgoitia A, Sanjurjo-Saez M. Information leaflets for patients with hepatitis $C$ receiving treatment with triple therapy. Eur J Hosp Pharm Sci Pract. 2013;20(1):13-9.

https://doi.org/10.1136/ejhpharm-2012-000176

51. Asavakarn S, Sirivatanauksorn Y, Promraj R, Ruenrom A, Limsrichamrern S, Kositamongkol P, Mahawithitwong P, Tovikkai C, Dumronggittigule W. Systematic Pharmaceutical Educational Approach to Enhance Drug Adherence in Liver Transplant Recipients. Transplant Proc. 2016;48(4):1202-7. https://doi.org/10.1016/j.transproceed.2015.12.100

52. Smith JP, Dong MH, Kaunitz JD. Evaluation of a pharmacist-managed hepatitis $\mathrm{C}$ care clinic. Am J HealthSyst Pharm AJHP OffJ Am Soc Health-Syst Pharm.
2007;64(6):632-6.

https://doi.org/10.2146/ajhp060153

53. Morillo-Verdugo R, Romero-Gómez M. Un nuevo escenario terapéutico en el tratamiento de la hepatitis crónica por virus C. Farm Hosp. 2012;36(6):466-8.

54. Marcoux RM, Simeone JC, Colavita M, Larrat EP. An Innovative Approach to Pharmacy Management in a State Correctional System. J Correct Health Care. 2012;18(1):53-61. https://doi.org/10.1177/1078345811421732

55. Rodis JL, Kibbe P. Development of a hepatitis C support group. Am J Health Syst Pharm. 2006;63(17):1594-6. https://doi.org/10.2146/ajhp050481

56. Hussein M, Benner JS, Lee D, Sesti A-M, Battleman DS, Brock-Wood C. Propensity score matching in the evaluation of drug therapy management programs: an illustrative analysis of a program for patients with hepatitis $\mathrm{C}$ virus. Qual Manag Health Care. 2010;19(1):25-33. https://doi.org/10.1097/QMH.0b013e3181ccbc7a

57. Veenstra DL, Higashi MK, Phillips KA. Assessing the cost-effectiveness of pharmacogenomics. AAPS PharmSci. 2000;2(3):80-90. https://doi.org/10.1208/ps020329

58. Carnevale RC, de Godoi Rezende Costa Molino C, Visacri MB, Mazzola PG, Moriel P. Cost analysis of pharmaceutical care provided to HIV-infected patients: an ambispective controlled study. Daru J Fac Pharm Tehran Univ Med Sci. 2015;23(1):13. https://doi.org/10.1186/s40199-014-0074-5

59. Menchen B, Folguera C, De rivas A, Saavedra V, Sanchez A. CP-149 Redesign of the management model and pharmaceutical care of patients with hepatitis $C$ virus infection. Eur J Hosp Pharm. 2016;23(Suppl 1):A66.1-A66. https://doi.org/10.1136/ejhpharm-2016-000875.149

60. Mehta BH, Rodis JL, Nahata MC, Bennett MS. Advancing patient care through innovative practice: The Clinical Partners Program. Am J Health Syst Pharm. 2005;62(23):2501-7. https://doi.org/10.2146/ajhp050017

61. Ministerio de Salud y Protección Social, Instituto de Evaluación Tecnológica en Salud. Vía clínica para el tratamiento de hepatitis C. Bogotá, D.C: Ministerio de Salud y Protección Social; 2017. 